Bureau of Mines Report of Investigations/1976

\title{
Electrokinetic Consolidation of Slimes in an Underground Mine
}



Report of Investigations 8190

\section{Electrokinetic Consolidation of Slimes in an Underground Mine}

By R. H. Sprute and D. J. Kelsh

Spokane Mining Research Center, Spokane, Wash.

UNITED STATES DEPARTMENT OF THE INTERIOR

Thomas S. Kleppe, Secretary

BUREAU OF MINES

Thomas V. Falkie, Director 
This publication has been cataloged as follows:

\section{Sprute, Richard H}

Electrokinetic consolidation of slimes in an underground mine / By R. H. Sprute and D. J. Kelsh, Spokane Mining Research Center, Spokane, Wash. [Washington] : Bureau of Mines, 1976.

30 p.: ill.; $26 \mathrm{~cm}$. (Report of investigations - Bureau of Mines ; 8190)

Bibliography: p. 22.

1. Tailings (Metallurgy). 2. Mine filling. 3. Mining engineering - Waste disposal. I. Kelsh, Dennis J , joint author. II. United States. Bureau of Mines. III. Title. IV. Series: United States. Bureau of Mines. Report of investigations - Bu• reau of Mines ; 8190 .

TN23.U7 no. $8190 \quad 622.06173$

U.S. Dept, of the Int, Library 


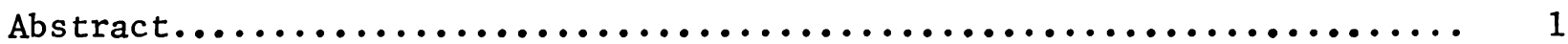

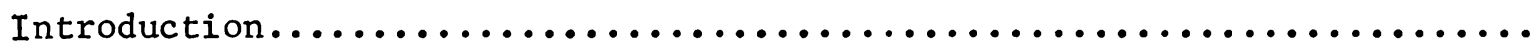

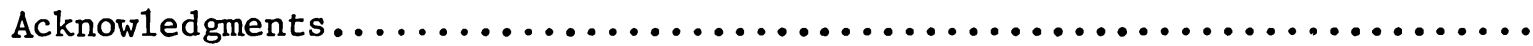

Test 1.--Electrokinetic treatment of new slime deposits.............

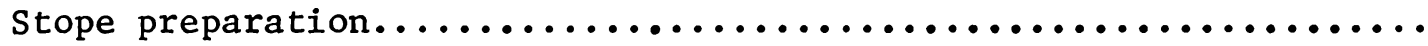

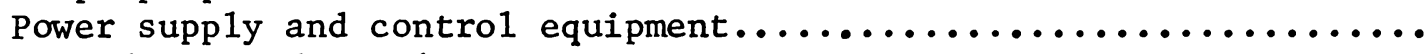

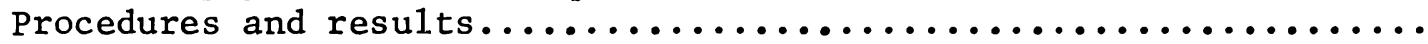

Test 2.--Electrokinetic treatment of old slimes..................

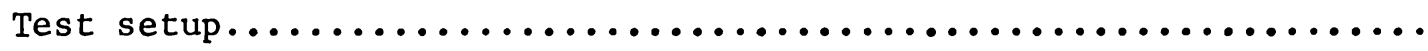

Electrical power and control equipment....................

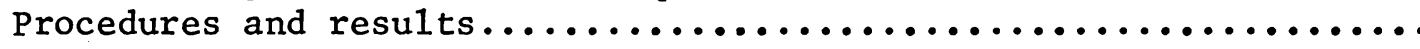

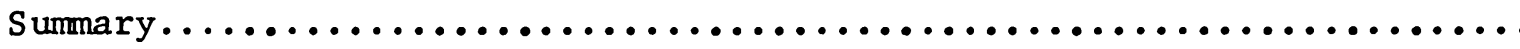

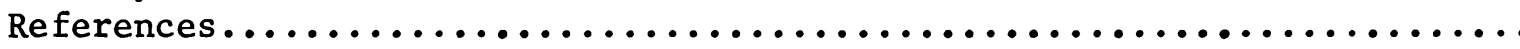

Appendix A.--Resistance calculations for slime deposits.............

Appendix B.--Potential safety hazards.........................

1

2

2

2

6

7

13

13

13

15

\section{IILUSTRATIONS}

1. Stope $\mathrm{MV}-1$ and 1 ayout for test $1 \ldots \ldots \ldots \ldots \ldots \ldots \ldots \ldots \ldots \ldots \ldots$

2. Suspended electrodes prior to filling.....................

3. Sandwa11 (minus headboard) ............................

4. Floating cathode ready for installation....................

5. Motor-generator unit, $12.5 \mathrm{kw} \ldots \ldots \ldots \ldots \ldots \ldots \ldots \ldots \ldots \ldots \ldots \ldots \ldots$

6. Electrical power and control diagram.....................

7. Grain size analysis of thickened slimes...................

8. Surface of slime fill after settling......................

9. Surface of fill after 4 hours of electrokinetic hardening........

10. Front section of stope after 25 hours of electrokinetic treatment.

11. Setup for test $2 \ldots \ldots \ldots \ldots \ldots \ldots \ldots \ldots \ldots \ldots \ldots \ldots \ldots \ldots \ldots \ldots \ldots \ldots \ldots \ldots$

12. Mobile motor -generator unit, $40 \mathrm{kw} \ldots \ldots \ldots \ldots \ldots \ldots \ldots \ldots \ldots \ldots \ldots$

13. Grain size analysis, test $2 \ldots \ldots \ldots \ldots \ldots \ldots \ldots \ldots \ldots \ldots \ldots \ldots \ldots \ldots \ldots$

14. Surface of slimes shortly after first applying power...........

15. Hardened surface at the end of treatment...................

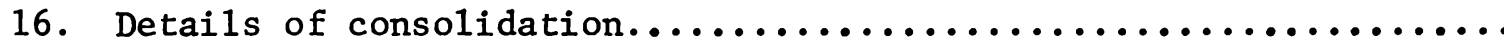

17. Face of treated material during removal procedure.............

A-1. Multicombination meter and soils box......................

A-2. Resistance calculations for test 2, section 1...............

B-1. Motor-generator unit used for treatment of slurries, $60 \mathrm{kw} . \ldots . .$.

$\mathrm{B}-2$. Electrica1 power and control schematic for a $60-\mathrm{kw}$ motor-generator set.......................................... 



\title{
ELECTROKINETIC CONSOLIDATION OF SLIMES \\ IN AN UNDERGROUND MINE
}

by

R. H. Sprute ${ }^{1}$ and D. J. Kelsh ${ }^{2}$

\begin{abstract}
The Federal Bureau of Mines conducted full-scale field tests in electrokinetic dewatering and consolidation of slimes in cooperation with the Hecla Mining Co. at two of the firm's underground mines in north Idaho.

To test the technique on new deposits, 4,000 $\mathrm{ft}^{3}$ of slimes from a collection sump, pumped into a watertight stope equipped with electrodes, were treated in two steps. Immediately after placement, direct current was applied using a floating electrode to hasten settlement of suspended fine particles. After removal of clarified water, the residue was further dewatered and hardened with electrokinetic treatment. In 25 hours, the material had become firm and dense with a surface capable of supporting workmen.

In testing old deposits, 10,000 $\mathrm{ft}^{3}$ of slimes, placed in an unused tail drift 10 to 12 months previously, were treated. This material was sufficiently consolidated by electrokinetics to allow its removal from the mine with standard ore-handling equipment.
\end{abstract}

In both tests, electrokinetic treatment densified slimes in a relatively short time with moderate power consumption.

\section{INTRODUCTION}

Mil1 tailings, the finely crushed waste from the ore-concentration process, are often used to backfill underground mine openings (stopes) in cut-and-fill operations. This backfill provides structural support and a base upon which men and equipment can effectively work in subsequent mining. Raw tailings, discharged from the mill circuit as a thin water slurry, usually contain a significant quantity of very fine-grained material (slimes) that settles too slowly to be used for backfill.

Electrical engineer.

${ }^{3}$ Professor of chemistry, Gonzaga University, Spokane, Wash.; employed part time at Spokane Mining Research Center, Spokane, Wash. 
To improve drainage, tailings are "classified," a process that separates the coarse fraction from the slimes, which are then placed in large aboveground ponds, behind dams, or in abandoned mine openings, where they remain fluid and noncohesive indefinitely. The coarse fraction is hydraulically transported underground into the stope to be backfilled. A relatively large quantity of water is normally used to transport the solids. For example, a typica1 100-foot-1ong, 8-foot-wide, 8-foot-high stope may require 50,000 gal of transport water. Most of this water is decanted during and after the filling process.

Although the backfill has been classified, it still contains considerable quantities of slimes. These fine particles do not settle out with the coarser classified grains, but remain in suspension and are carried along with the decanted water to large collection sumps. There, they are given longer time for settlement, and clear surface water develops. It decants into sumps and is pumped out of the mine. The thickened slime residue is transferred into abandoned mine openings, impounded behind dams across unused tail drifts, etc. These slimes never dewater and consolidate sufficiently by gravity settlement alone to form useful fill.

Recent work by the Bureau at its Spokane Mining Research Center has shown that electrokinetics can effectively consolidate and harden these materials. Smal1-scale laboratory tests in electrokinetic treatment of slimes from various metal mines provided data on power requirements, procedures, and the amount of dewatering and densification that could be expected $(3-4) .{ }^{3}$ To validate these results and to demonstrate the technical and economic feasibility of electrokinetic treatment, full-scale field tests were conducted in cooperation with the Hecla Mining Co. in two of their mines in the Coeur d'Alene mining district of north Idaho.

Obviously some potential hazards are present with the application of direct current to backfill in underground mines. Identification of the major hazards with procedures to reduce or eliminate them are presented in appendix B.

\section{ACKNOWLEDGMENTS}

The cooperation of the Hecla Mining Co. is gratefully acknowledged. Special recognition is due Hecla employees Walter Paroni, engineer, whose liaison duties included scheduling, planning, and technical assistance, and Terry Ostwald, electrician, who helped with equipment installation and operation, data collection, and other technical work.

\section{TEST 1.--ELECTROKINETIC TREATMENT OF NEW SLIME DEPOSITS}

\section{Stope Preparation}

Stope MV-1, off the 7500-foot level of the Star mine, was selected as the test site. As shown in figure 1, the stope measured about 80 feet long by

3 Underlined numbers in parentheses refer to items in the list of references preceding the appendixes. 


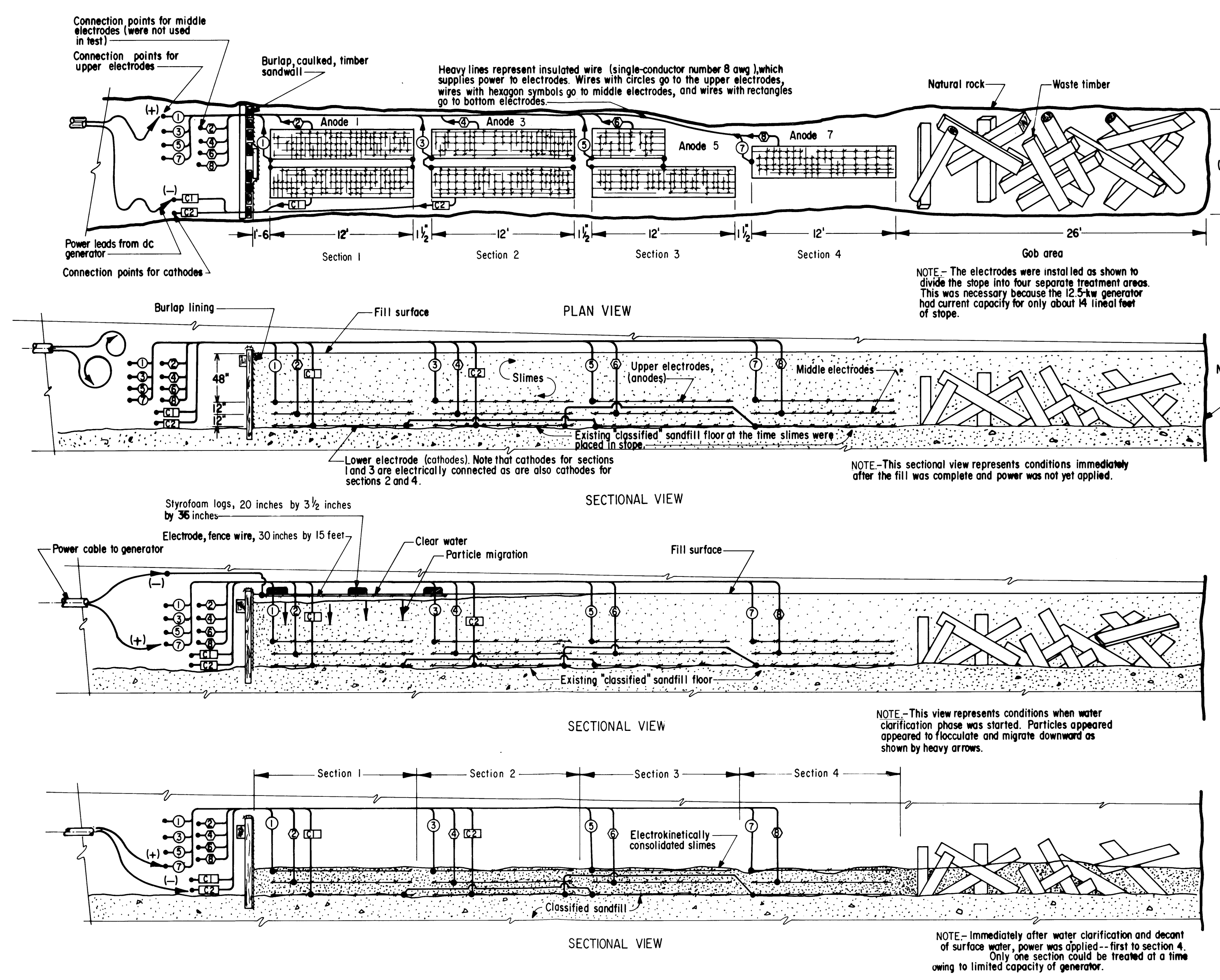

FIGURE 1. - Stope MV-1 and layout for test 1. 
6 feet high, with an average width of 8-1/2 feet. The waste timber from stoping operations at the tail end of the stope ("gob area") was secured and boarded off to prevent it from floating over the treatment area during backfilling.

The stope was divided into four treatment sections, each 14 feet long (fig. 1). With this arrangement, treatment could be limited to one 14 -foot section, which is the maximum area the small $12.5-\mathrm{kw}$ (55-amp) generator could effectively handle. Each section was fitted with three 12 -foot-1ong horizontal electrodes made from 14 -gage iron hog wire.

Figure 2 shows the suspended electrodes in place prior to filling the stope. The bottom electrodes (cathodes) were laid directly on the existing permeable sandfill and the top electrodes (anodes) were held in place with lagging and nylon line. Vertical distance between top and bottom electrodes was set at 24 inches because previous experience indicated that a 5-foot depth of slimes would reduce to about 30 inches after removal of surface water and electrokinetic treatment of the residue.

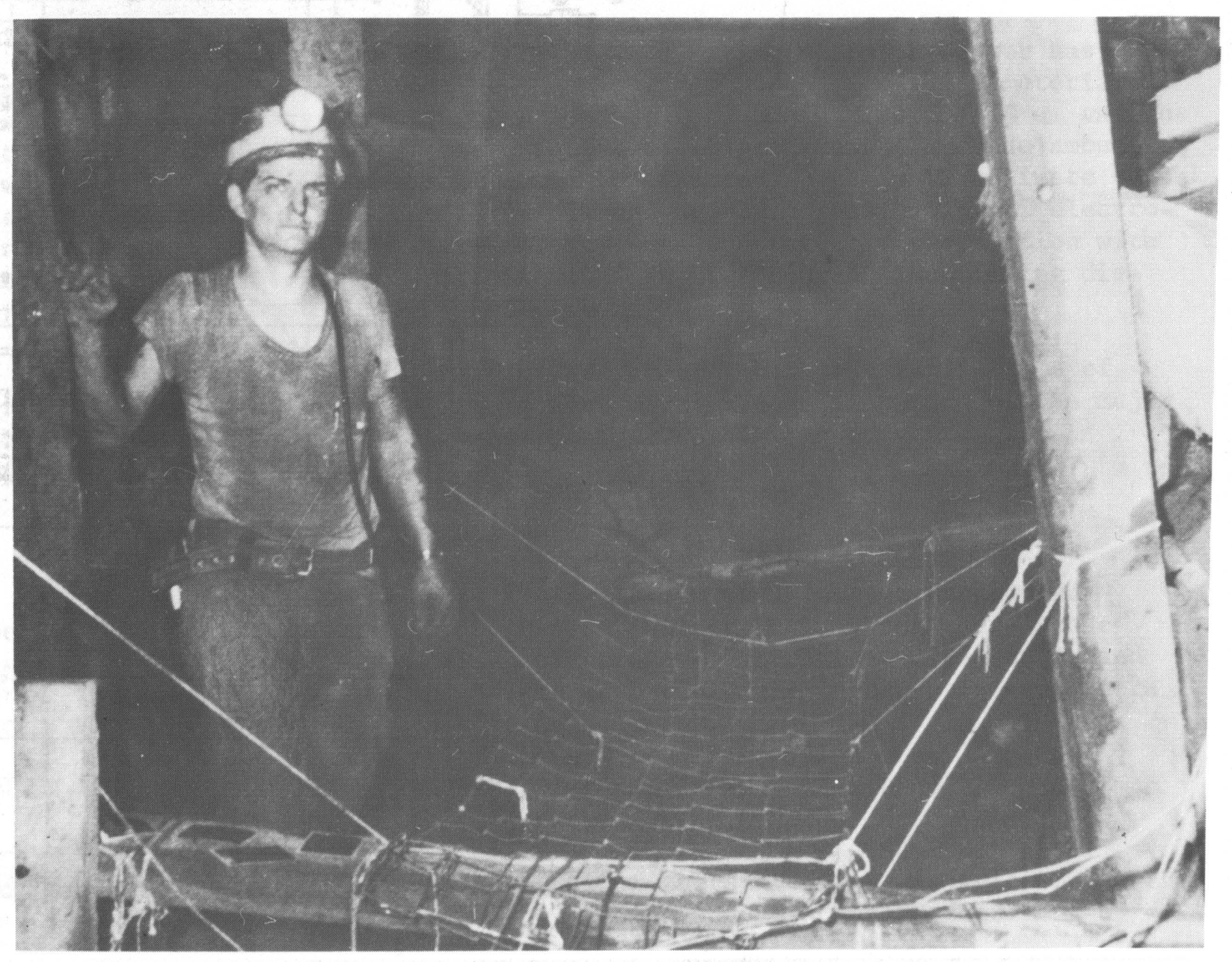

FIGURE 2. - Suspended electrodes prior to filling. 
A third set of electrodes, which could be used either as anodes or cathodes, was held in place with nylon line midway between the top and bottom electrodes. These electrodes were installed to allow for the increasing resistivity of the slimes during treatment, possibly to the extent that the maximum generator output of 220 volts would be insufficient to treat a 24 -incl layer. In this case, during each 30 min of treatment, power would be automatically applied for 15 min to the 12 -inch layer between the top two electrodes (middle electrode positive) and then to the 12 -inch layer between the bottom two electrodes for $15 \mathrm{~min}$ (middle electrode negative). As it turned out, resistivity of the slimes remained much lower than expected through the entire treatment period and the middle electrode was not required.

A burlap-backed sandwal1 (fig. 3), essentially watertight, was constructed across the stope to impound the slimes. Separate insulated electrical power leads were attached to each of the electrodes except for those on the stope floor, where one lead served two electrodes. The power leads were routed over the sandwall to an accessible area that allowed easy connection to any desired combination of electrodes.

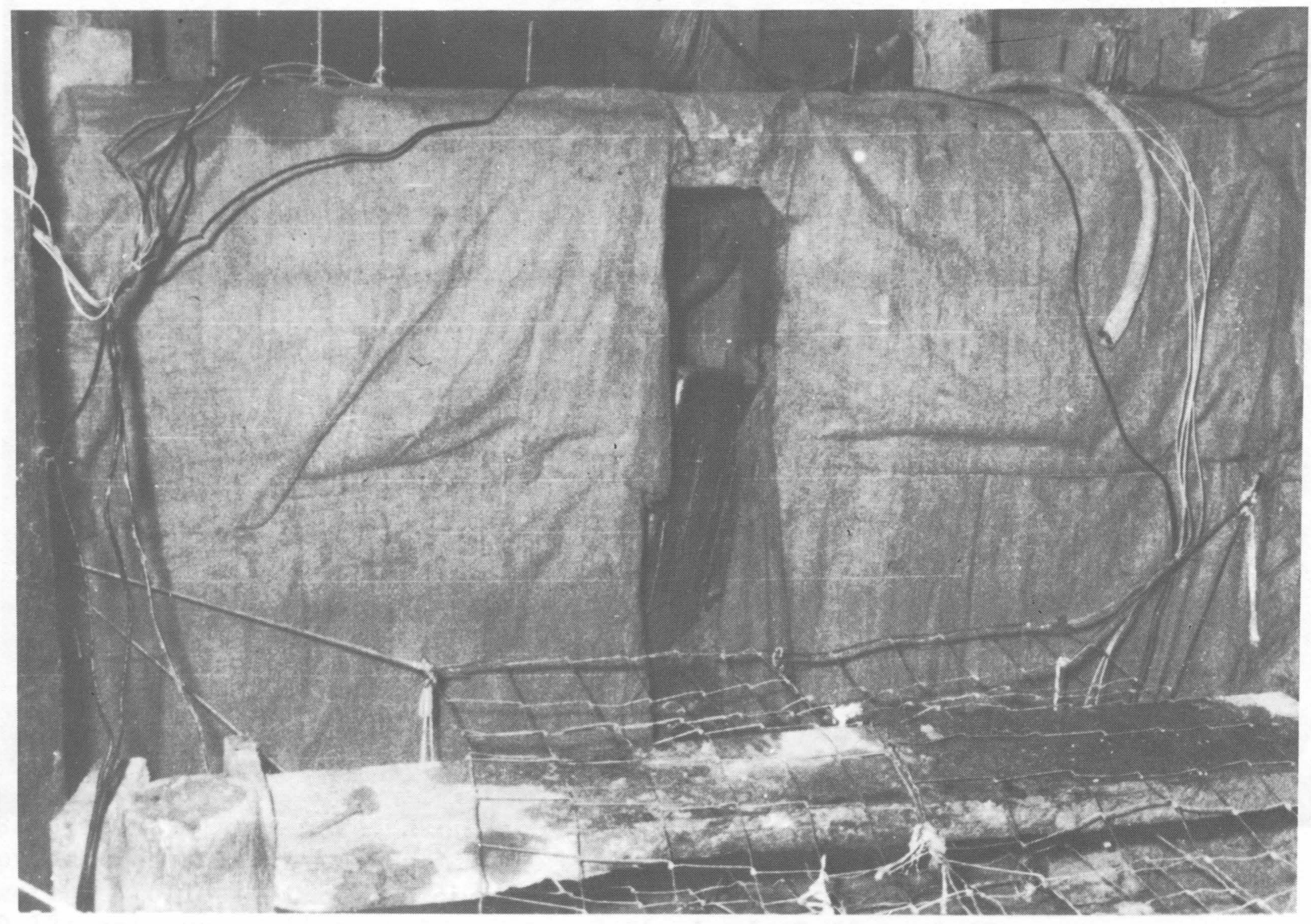

FIGURE 3. - Sandwall (minus headboard). 
To hasten the settlement of the slimes, a fourth electrode, a floating cathode, was prepared by attaching a 16-foot length of hog wire to four Styrofoam ${ }^{4}$ floats, each $3-1 / 2$ by 20 by 36 inches (fig. 4). This was placed on the slime surface and energized immediately after the stope was filled.

\section{Power Supply and Contro1 Equipment}

Direct current required for the test was obtained from a $12.5 \mathrm{kw}$ generator driven by a 20-hp, 440-volt, three-phase ac motor (fig. 5). The generator had a maximum current rating of 55 amp with output voltage manually adjustable between 60 and 220 volts. As shown in the schematic diagram (fig. 6), power was applied to the electrodes through two 2 -pole contactors. A clock-operated programer automatically controlled the contactors, applying power continuously or intermittently, or continuously alternating power from one pair of electrodes to another, such as between top and middle electrodes, then to the middle and bottom, etc.

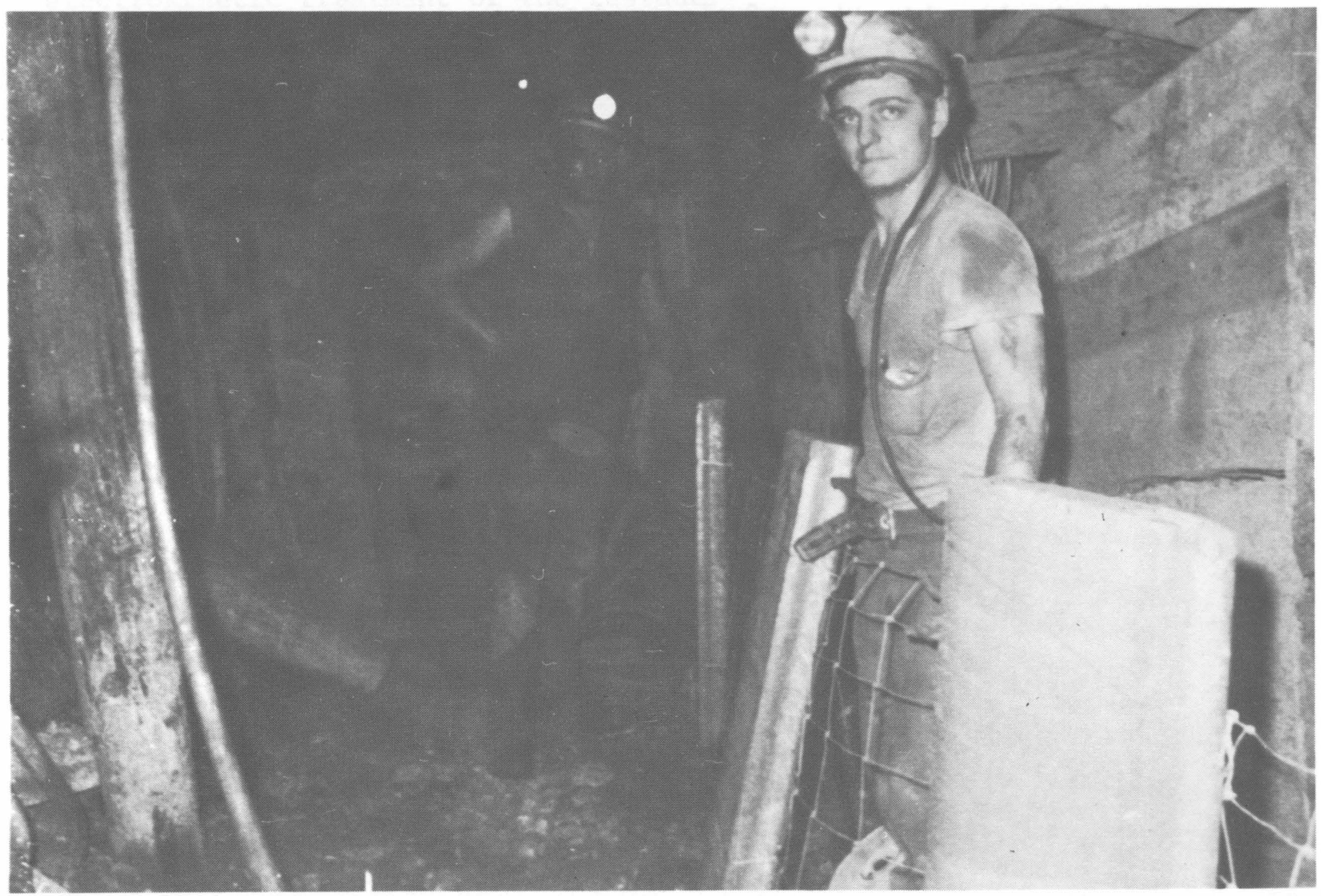

FIGURE 4. - Floating cathode ready for installation.

${ }^{4}$ Reference to specific trade names is made for information only and does not imply endorsement by the Bureau of Mines. 


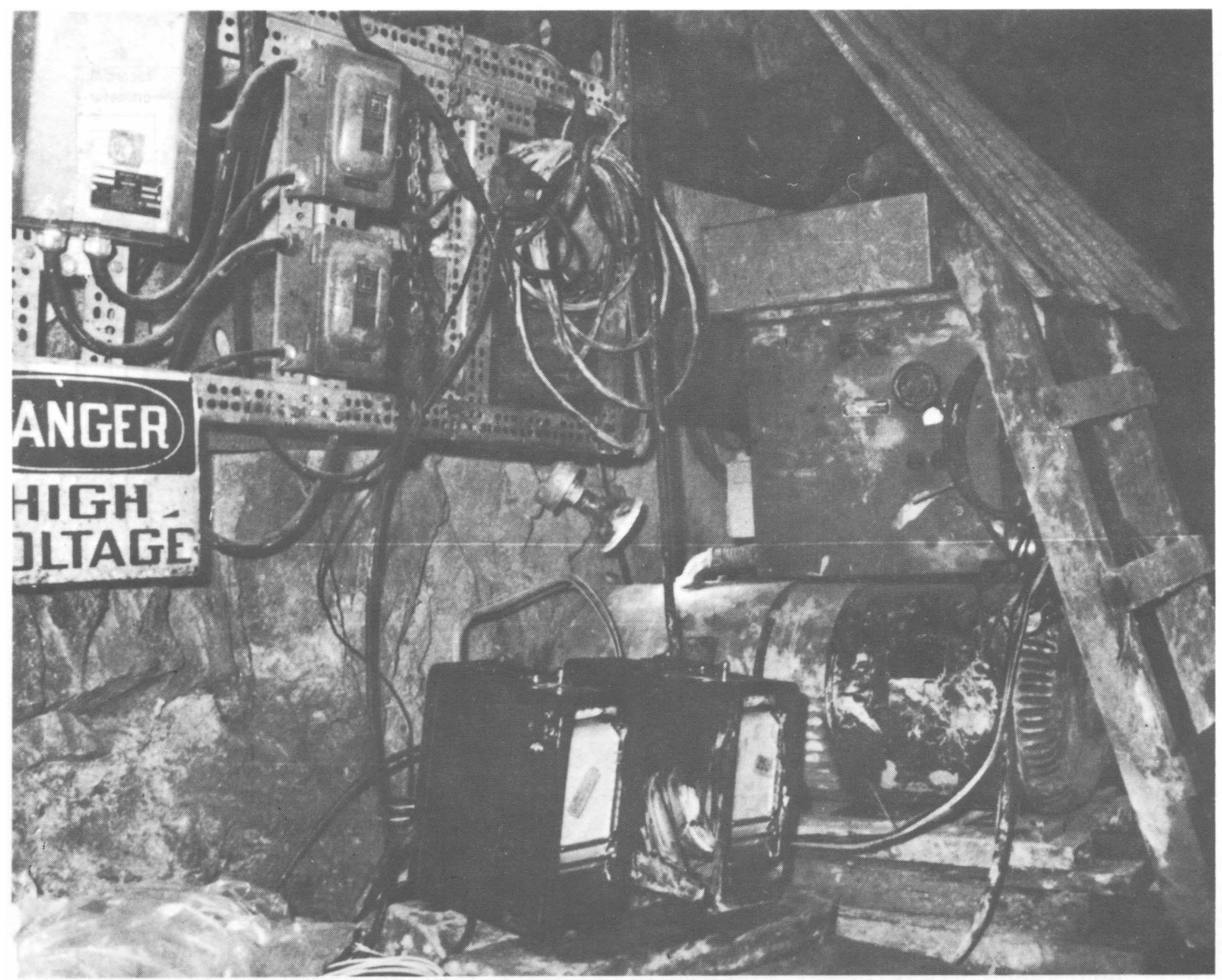

FIGURE 5. - Motor-generator unit, $12.5 \mathrm{kw}$.

Strip-chart recorders continuously recorded dc power consumption (watts) and current flow. Chart speed was $3 \mathrm{in} / \mathrm{hr}$ and the accuracies of the wattmeter and ammeter according to criteria of the American Standards Association (ASA) were listed as within 3.0 and 1.5 pct, respectively.

\section{Procedures and Results}

About 4,000 $\mathrm{ft}^{3}$ of thickened slimes were pumped from a full collection sump into the prepared stope, filling it to within 12 inches of the top. Samples of slimes were taken during pouring for determination of physical properties and spectrographic analysis. The principal metallic components were as follows, in weight-percent: aluminum, 1.9 to 3.2 ; boron, 0.10 to 0.12 ; calcium, 0.11 to 0.13 ; iron, 7.34 ; lead, 0.60 to 0.62 ; magnesium, 0.80 to 0.91 ; manganese, 0.83 ; silicon, 30.1 to 30.5 ; and titanium, 0.15 to 0.17 . Cation-exchange capacity ranged from 1.0 to 1.1 milliequivalents per 100 grams, and resistivity was $830 \mathrm{ohm}-\mathrm{cm}$ at $21^{\circ} \mathrm{C}$. The particle-size distribution is displayed graphically in figure 7 . 


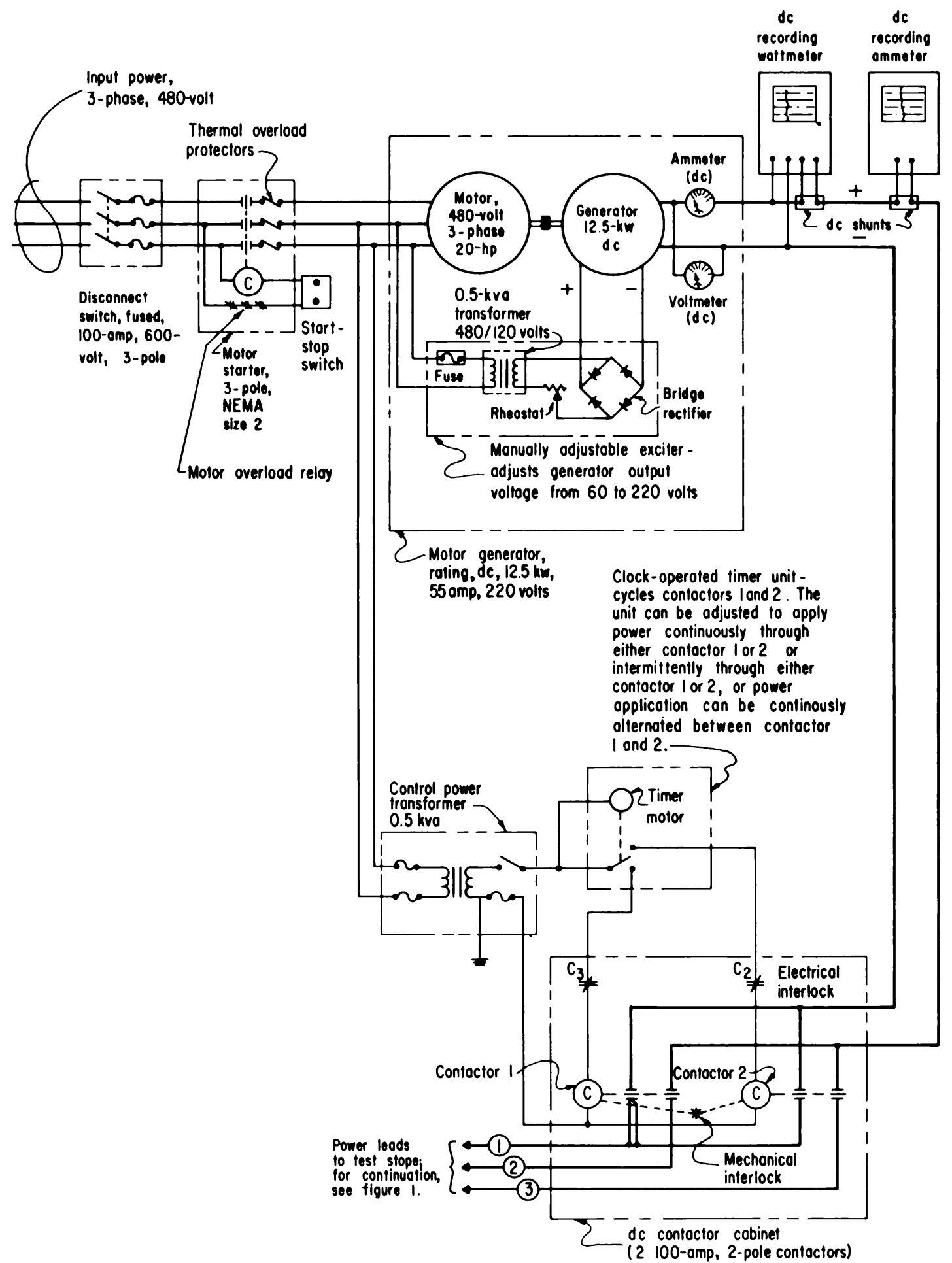

FIGURE 6. - Electrical power and control diagram.

Immediately after the stope was filled, the floating electrode was placed on the surface of the slimes and dc power was applied. The floating electrode 


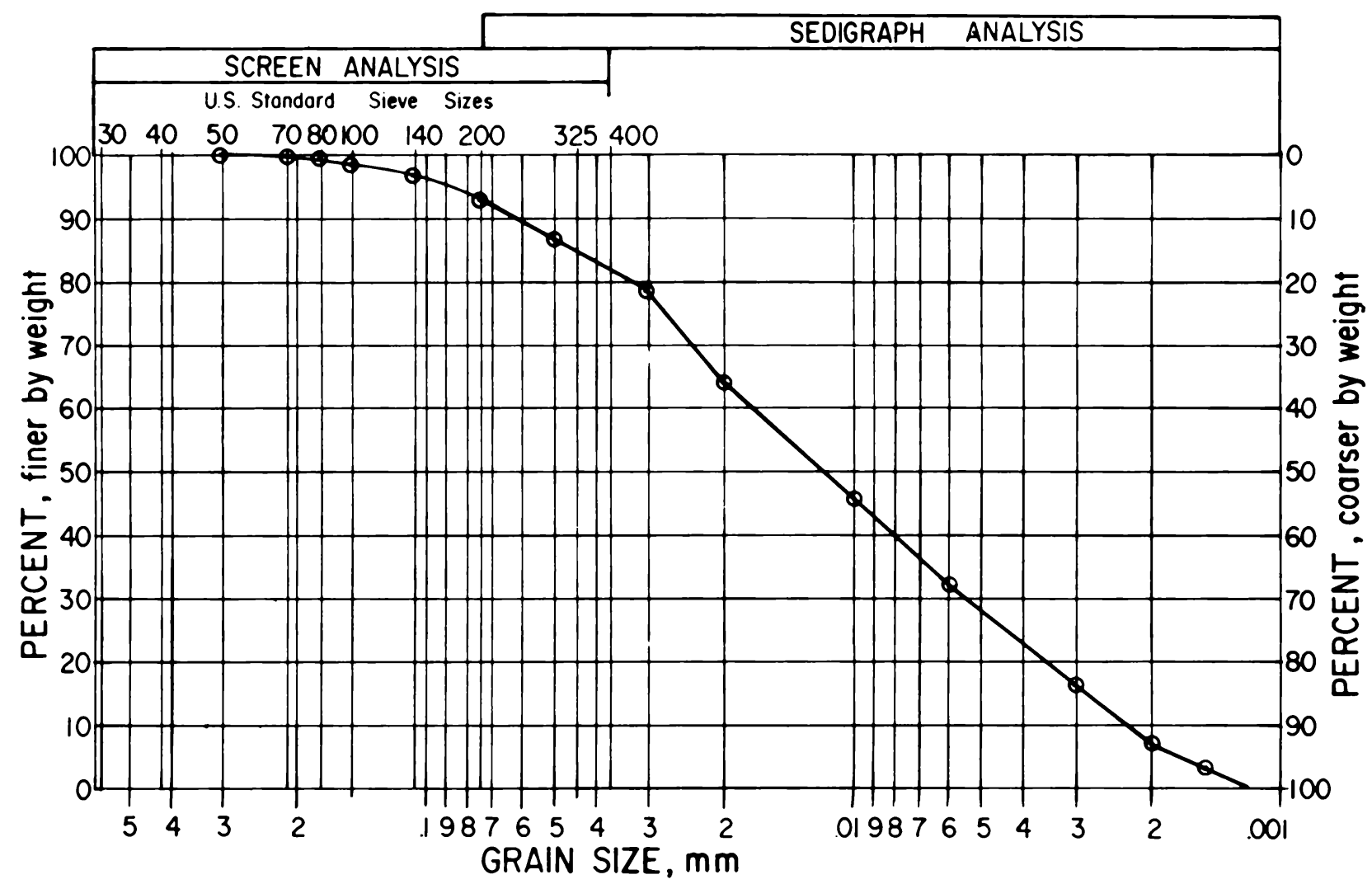

FIGURE 7. - Grain size analysis of thickened slimes.

was made negative (cathode), and the bottom electrode became the anode (fig. 1, middle sectional view). Current was adjusted to about 55 amp at 150 volts. With this rather dense current flow (1.38 amp/ $\mathrm{ft}^{2}$ immediately under the floating electrode), particles migrated downward, and a clear layer of water from $1-1 / 2$ to 3 inches deep quickly developed under the surface electrode.

As clarification progressed, the burlap caulking across five or six 1 -inch-wide vertical spaces in the sandwall was cut downward in such a manner that the slits extended from the top to the bottom of the clear layer, thus permitting only clear water to escape. The maximum rate of removing clear water by this method, as measured by change of surface elevation, was about $1,500 \mathrm{gal} / \mathrm{hr}$. Even at this removal rate, however, a clear zone from 1 to 2 inches constantly remained under the floating electrode, indicating that with a better water-removal system, an even greater rate of clarification might be realized. In any case, all surface water was clarified in 5 hours using only $37 \mathrm{kwhr}$ of power. The surface electrode was removed when all but about 1 inch of surface water was gone.

Settlement was allowed to continue overnight (12 hours) without power application (fig. 8). Slurry level lowered approximately 4 inches during this period in contrast to the 12 -inch lowering during the previous 5 -hour period of electrophoretic-assisted settling. A clear layer of water $1 / 2$ to 1 inch deep covered most of the surface. 


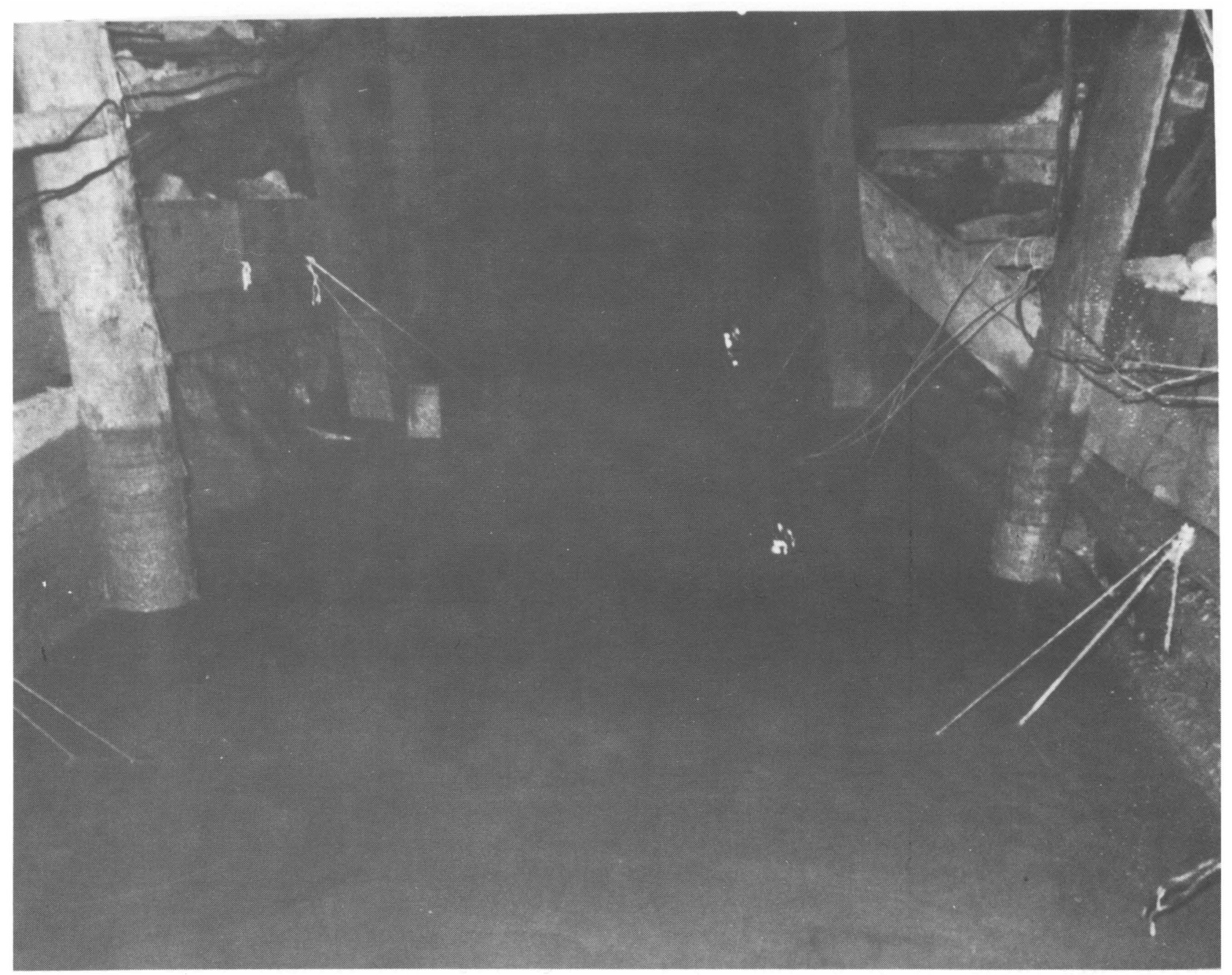

FIGURE 8. - Surface of slime fill after settling.

Electrokinetic consolidation of the settled slimes was accomplished by separately treating each of the four 14-foot sections of the stope. Periodic direct current ( $25 \mathrm{~min}$ on, $5 \mathrm{~min}$ off) was used, with power applied between the top and bottom electrodes as shown in the bottom sectional view of figure 1, driving the water downward to be discharged through the classified sandfill at the base of the stope. The middle electrode served no useful purpose because the resistance of the settled slimes remained low, and closer spacing of the electrodes was not required.

Electrokinetic treatment of the settled slimes started on November 16, 1974, the day after the water-clarification step. About 55 amp of dc current $\left(500 \mu \mathrm{a} / \mathrm{cm}^{2}\right)$ was applied to section 4 , the back quarter of the fill, for 4 hours, and then to the second section from the front for about 2 hours. During this period, the remaining one-half inch of surface water disappeared into the solids, clearly demonstrating the effectiveness of the electroosmotic force in dewatering fine material. Consolidation was indicated by shrinkage 
cracks, particularly along the walls, and a decidedly concave surface (fig. 9). Power was off for 18 hours because of equipment failure and was then reapplied to section 2 for 2.5 hours on November 17 .

Section 1 (nearest the sandwa11) was next treated continuously for 25 hours, after which material in this section was hard enough to support workmen (fig. 10). Section 2 dewatered considerably during this period, even though current was applied solely to the front section.

From noon, November 18, unti1 7:30 a.m., November 19, sections 2 and 3 were treated simultaneously with 200 volts and a total current of 60 amp $\left(270 \mathrm{\mu a} / \mathrm{cm}^{2}\right)$. Although good consolidation occurred with this low current density, as evidenced by cracks, etc., the material remained considerably softer than that in section 1 .

Total treatment times and power consumption were as follows: 25 hours and $210 \mathrm{kwhr}$ for section 1; 13 hours and $140 \mathrm{kwhr}$ for section 2; 10 hours and

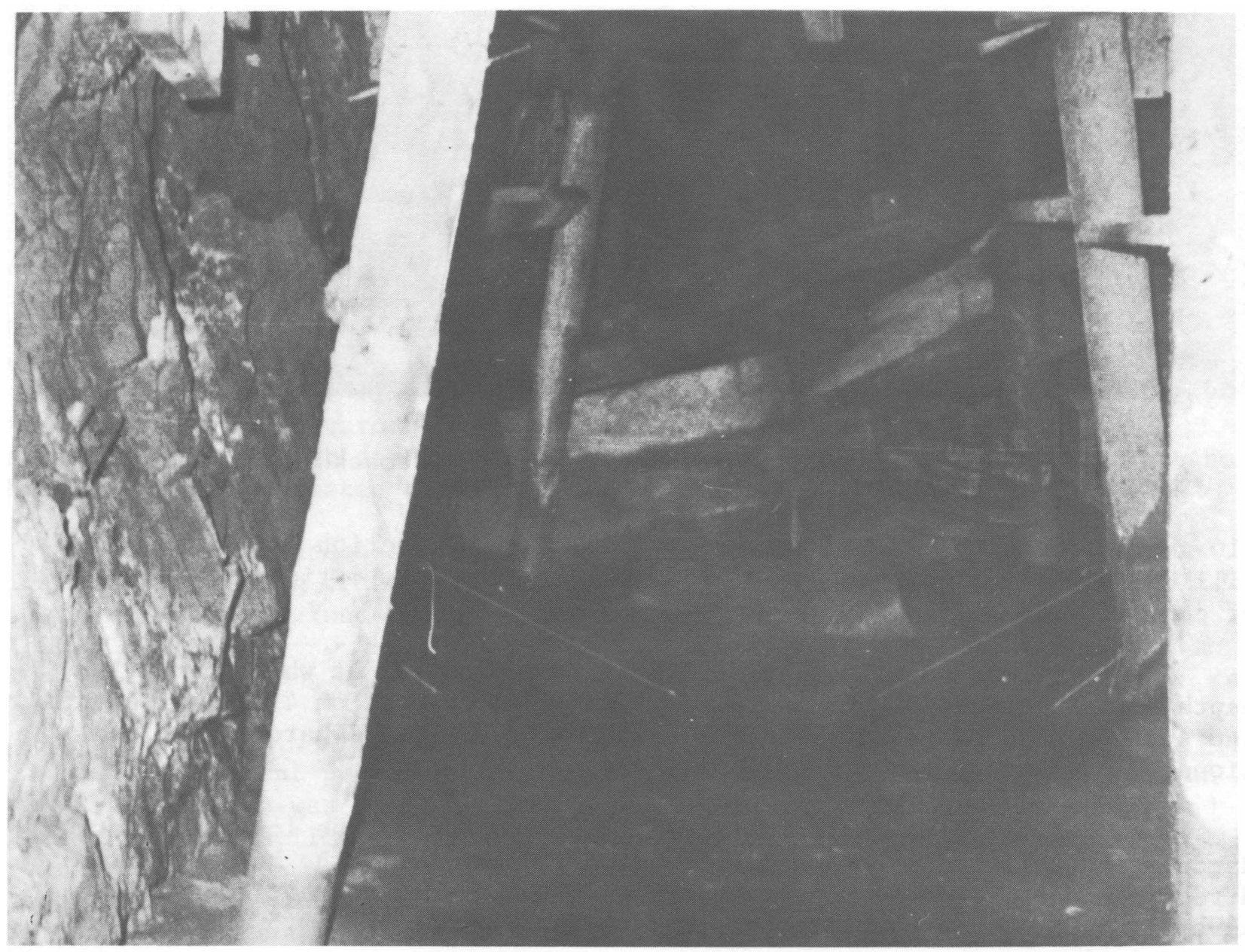

FIGURE 9. - Surface of fill after 4 hours of electrokinetic hardening. 


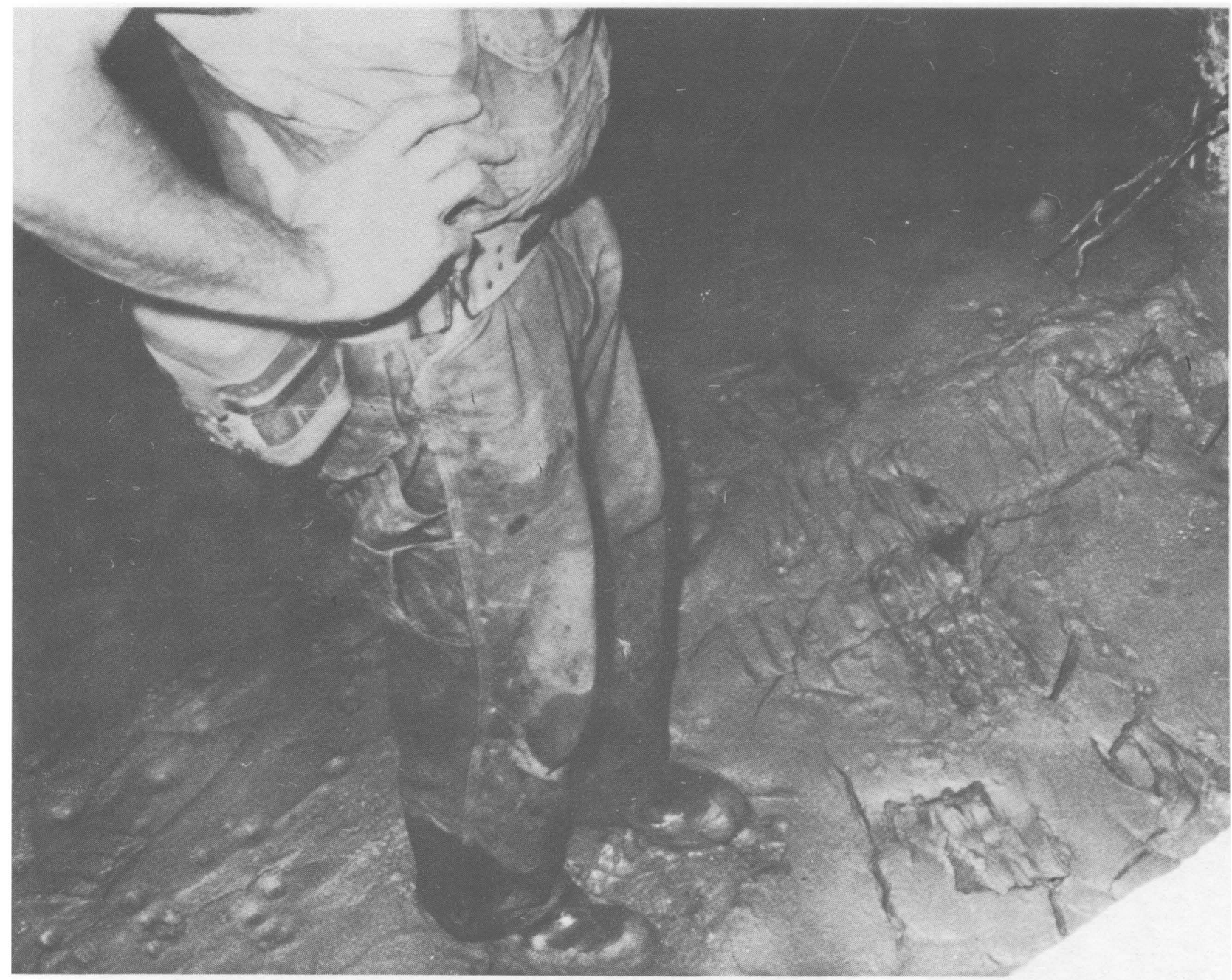

FIGURE 10. - Front section of stope after 25 hours of electrokinetic treatmeni.

$110 \mathrm{kwhr}$ for section 3 ; and 4 hours and $30 \mathrm{kwhr}$ for section 4. The $150 \mathrm{yd}^{3} \mathrm{of}$ fill had consolidated to about $60 \mathrm{yd}^{3}$ with a power consumption of $8.2 \mathrm{kwhr} / \mathrm{yd}^{3}$ of consolidated fill.

Treatment was concluded at 7:30 a.m., November 19, at which time fill depth varied between 24 and 30 inches. Material in section 4 was quite soft, and surface-hardness measurements were not made. Surface hardness in sections 2 and 3 ranged from 0 to 40 psi.

Best results were achieved in section 1 , which had the longest treatment. Hardness in this section ranged from 40 to 250 psi, with the hardest material directly under the anode. Average dry-weight moisture content and density of several samples taken beneath the anode were $30.2 \mathrm{pct}$ and $93.51 \mathrm{~b} / \mathrm{ft}^{3}$, respectively. 
The total time expended for treatment in this test is more than would normally be available in cut-and-fill mining cycles. Process time could be reduced to an acceptable level by using a power supply with sufficient capacity to treat an entire stope in a single operation.

Classified (coarse) sandfill was placed on top of the hardened slimes in the normal manner. No problems were encountered during further excavation and removal of ore.

In January 1975, the preceding test was repeated in the Lucky Friday mine, Wallace, Idaho, on slime deposits, with some differences. The waterclarification step was omitted because suspension of fine solids was not a severe problem. Also, availability of a larger generator (40 kw) permitted a simpler electrode system. Electrodes were lengths of 5 -foot-wide iron fence wire. The cathode was placed on the stope floor, and the anode was supported 30 inches above the floor. After complete settlement of solids, surface water was decanted and the residue was electrokinetically dewatered and consolidated in 26 hours of treatment. A1though physical properties and composition of the $3,000 \mathrm{ft}^{3}$ of slimes in this test differed somewhat from material in the first test, results were quite similar.

\section{TEST 2.--ELECTROKINETIC TREATMENT OF OLD SLIMES}

\section{Test Setup}

To determine if electrokinetics could sufficiently dewater and densify old slimes to permit handling with standard equipment (such as muckers, ore cars, and skips), a large deposit of old slimes on the 4050 level of one of Hecla's deep metal mines was selected as suitable test material. The deposit was about 150 feet long by 10 feet wide by 5 feet deep (fig. 11). The deposit contained substantial mineral value, resulting from enrichment while flowing to collection sumps through haulage areas where ore spillage occurs. The slimes were very soft and showed no tendency to dewater or consolidate further. Mine personnel estimated the slimes to be from 10 to 12 months old.

No provision had been made beforehand for electrokinetic treatment. Therefore, existing ore car rails were used as the bottom electrodes, and 14-gage iron mesh fence wire on the surface served as the upper electrode (fig. 11).

\section{Electrical Power and Contro1 Equipment}

Direct current power was obtained from a motor generator set mounted on a timber car, which was complete with power contactors, control equipment, and $120 / 240$ volt ac utility power (fig. 12). The dc generator, rated at $40 \mathrm{kw}$, 240 volts, and 165 amp, was driven by a 50-hp, 440-volt, three-phase, ac induction motor. This motor generator set was equipped with a long, fourconductor cable and a male connector on the input side; this allowed the generator to be easily and quickly moved to any area on the 4050 level requiring electrokinetic treatment. Control features were similar to those used for the generator, in test 1 , except for the addition of a constant 


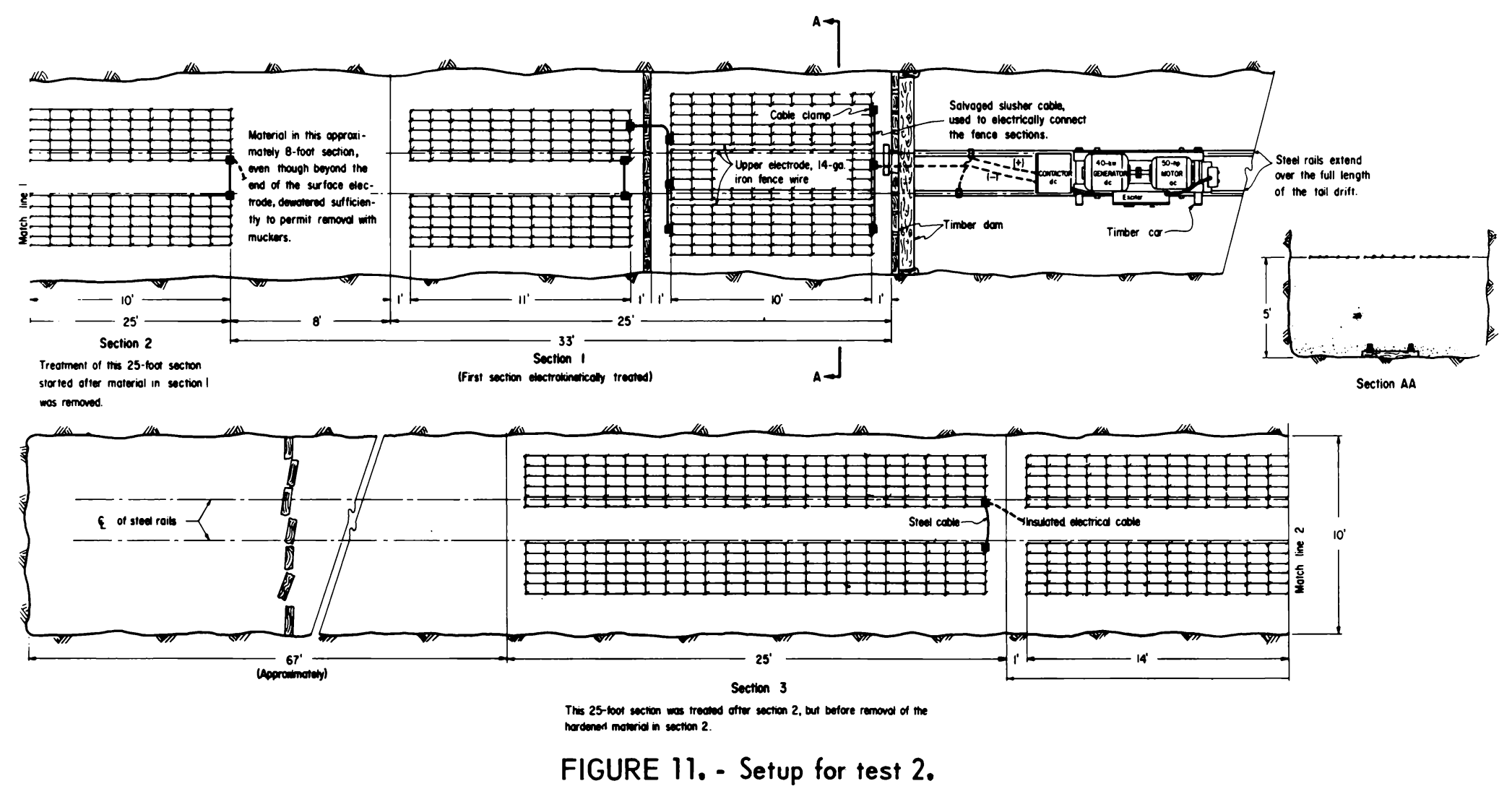




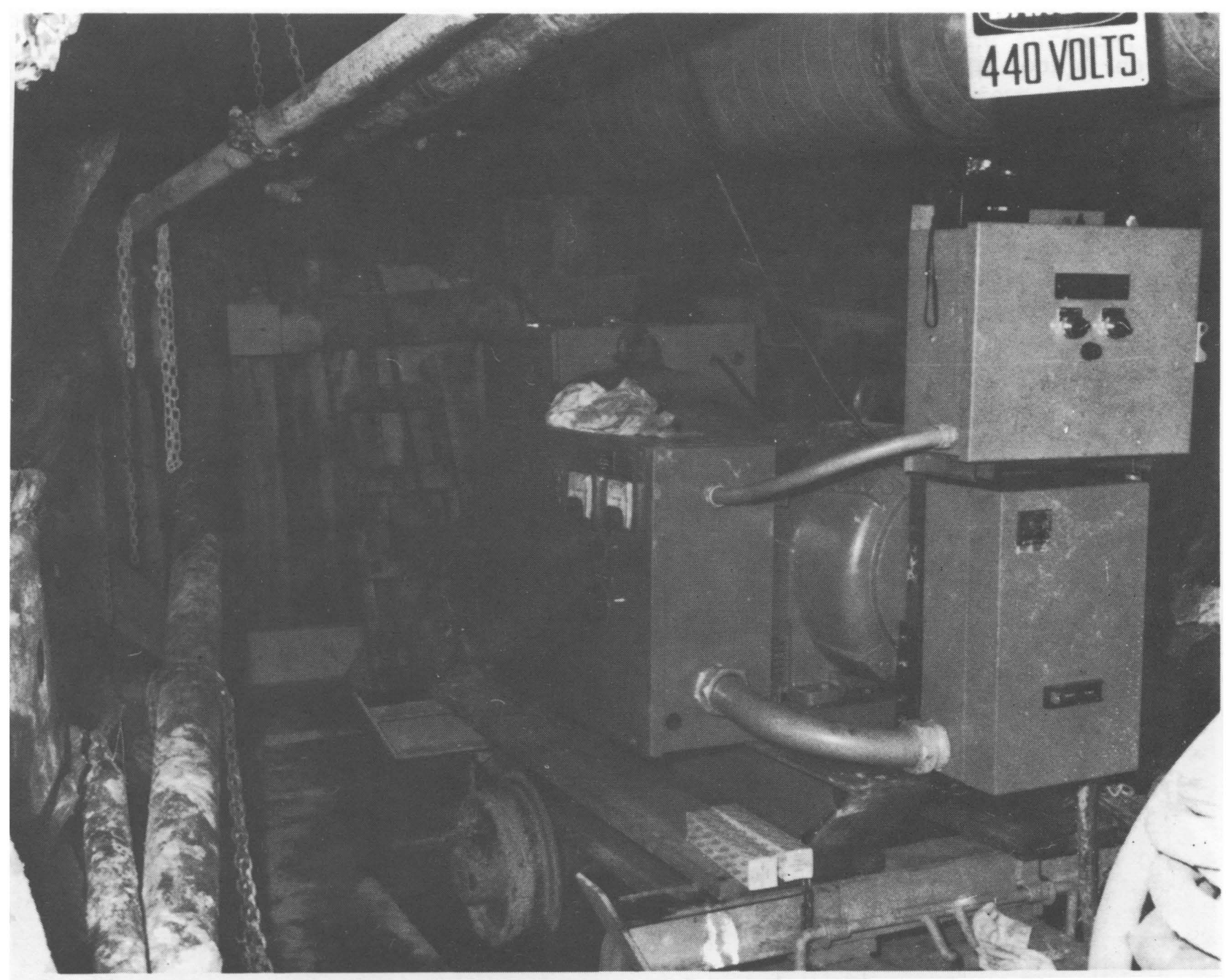

FIGURE 12. - Nobile motor-generator unit, $40 \mathrm{kw}$.

current regulator. This permitted current to be automatically maintained at any preset value regardless of resistivity changes in the slimes being treated. Equipment for recording power and current was identical to that used in test 1.

\section{Procedures and Results}

Previous small-scale laboratory tests by the Spokane Mining Research Center on slime samples from this mine indicated that a current density of 600 to $800 \mathrm{ma} / \mathrm{cm}^{2}$ (0.56 to $0.75 \mathrm{amp} / \mathrm{ft}^{2}$ ) is required for best dewatering results (4). A maximum generator rating of 165 amp, derated 30 pct because of high ambient temperature in the tail drift, limited treatment to about $250 \mathrm{ft}^{2}$ or 25 lineal feet of the dam. As indicated in figure 11, three such sections were treated during the test.

Samples were taken about 35 feet from the front of the stope before treatment and spectrographically analyzed by the Bureau's Albany Metallurgy 
Research Center at Albany, Oreg. The following were the principal metallic components in weight-percent: aluminum, 7.35 to 7.84 ; calcium, 2.98 to 4.14; iron, 4.35 to 4.61 ; lead, 1.56 to 2.05 ; magnesium, 0.01 to 0.1 ; manganese, 0.39 to 0.40 ; silicon, 26.0 to 26.5 ; and titanium, 0.45 to 0.49. . Fire assay analysis of four samples performed by the Bureau's Reno Metallurgy Research Center in Reno, Nev., revealed a silver content ranging from 1.8 to $2.4 \mathrm{oz} / \mathrm{ton}$. Silver and lead contents were particularly significant because they were high enough to justify returning the material to the mill for reprocessing. Cationexchange capacity was determined by the Oregon State University Soils Testing Laboratory, Corvallis, Oreg., to be 3.3 milliequivalents per 100 grams. Grain size analysis is shown in figure 13. Resistivity measured in a Miller soils box at the Spokane Mining Research Center was $950 \mathrm{ohm}-\mathrm{cm}$. Appendix A briefly describes how these resistivity measurements can be used to calculate the total resistance of slimes between electrodes placed in a slime deposit.

In dewatering the first section, positive potential was applied to both rails on the floor of the drift beneath the slimes (fig. 11). The rails, probably electrically continuous over most of the 4050 leve1, were at ground potential. Negative potential was applied to 30 -inch-wide fence wire laid on the surface of the slimes. Intermittent power was applied (25 min on, $5 \mathrm{~min}$ off), and current was set at $125 \mathrm{amp}\left(0.78 \mathrm{amp} / \mathrm{ft}^{2}\right.$ of surface electrodes) at a potential of 225 volts.

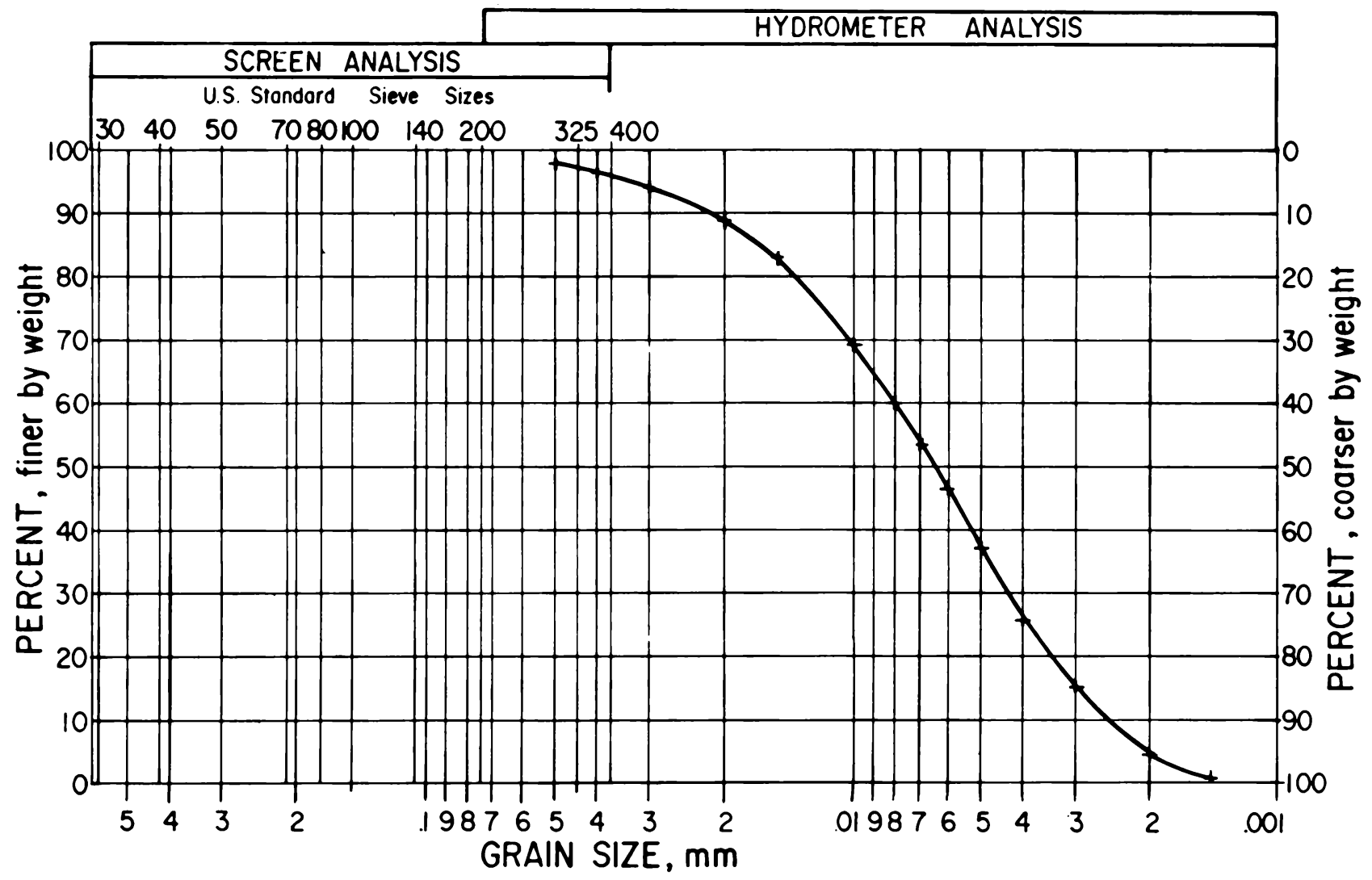

FIGURE 13. - Grain size analysis, test 2. 
Immediately after power application, water emerged from the surface, filling voids and depressions as shown in figure 14. Small channels, scratched on the surface with a pole, routed water over the end of the dam. An interesting observation at this point was how closely water flow corresponded with current flow. Water flow essentially stopped 1 or 2 minutes after power was interrupted, and began again as quickly when the power was restarted.

Consolidation was evident a few hours after treatment started. The surface subsided, and cracks and voids developed between drift walls and material. The material was treated for 53 hours with a power consumption of $30 \mathrm{kwhr} / \mathrm{yd}^{3}$. A total of 18 surface-hardness measurements were taken with a Soil Test Penetrometer and ranged from 160 to 0 psi, with an overall average of $60 \mathrm{psi}$. Hardest material was under the top electrodes with very soft material ( 0 to $10 \mathrm{psi}$ ) immediately adjacent to the drift wa1ls. As indicated in figure 11, consolidation and dewatering were effective to about 8 feet

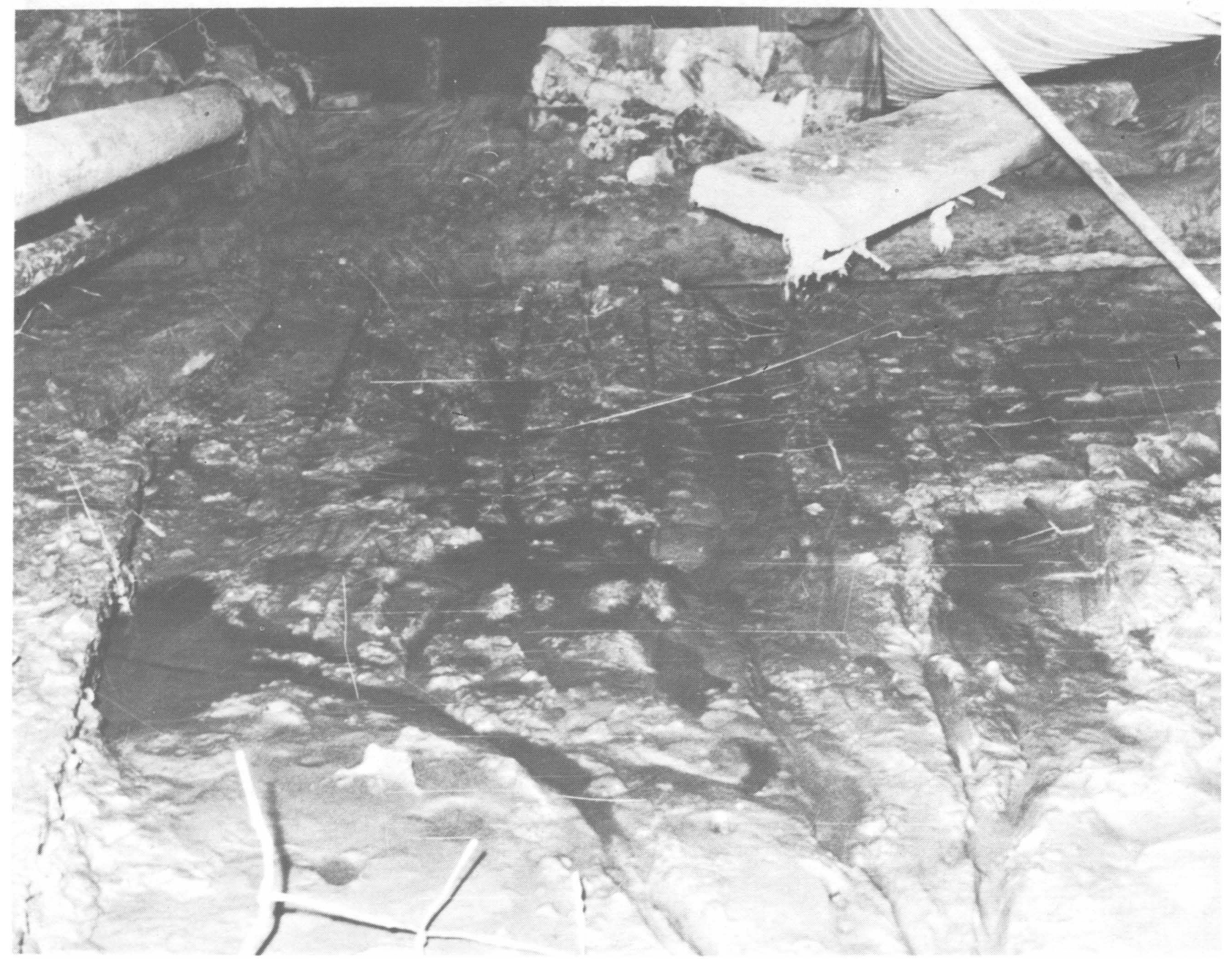

FIGURE 14, - Surface of slimes shortly after first applying power. 
beyond the end of the top electrodes, possibly because the bottom electrode (rails) extended over the full length of the drift. Figure 15 shows a view of the hardened surface, and figure 16 shows consolidation; that is, lowered elevation of the surface and large voids between material and the drift wall.

The consolidated slimes were satisfactorily removed from the drift with a mucker shortly after treatment, and from the mine with ore cars and skips. Figure 17 shows the freestanding wall during the mucking operation. As indicated, the upper two-thirds layer was more dense than the lower one-third.

It is probable that the entire mass, particularly the softer area, could have been hardened further with continued treatment. However, the mine operators correctly diagnosed the material to be dry and hard enough for easy remova1. After removal of 34 lineal feet of hardened materia1, treatment of the next 25 -foot section was started.

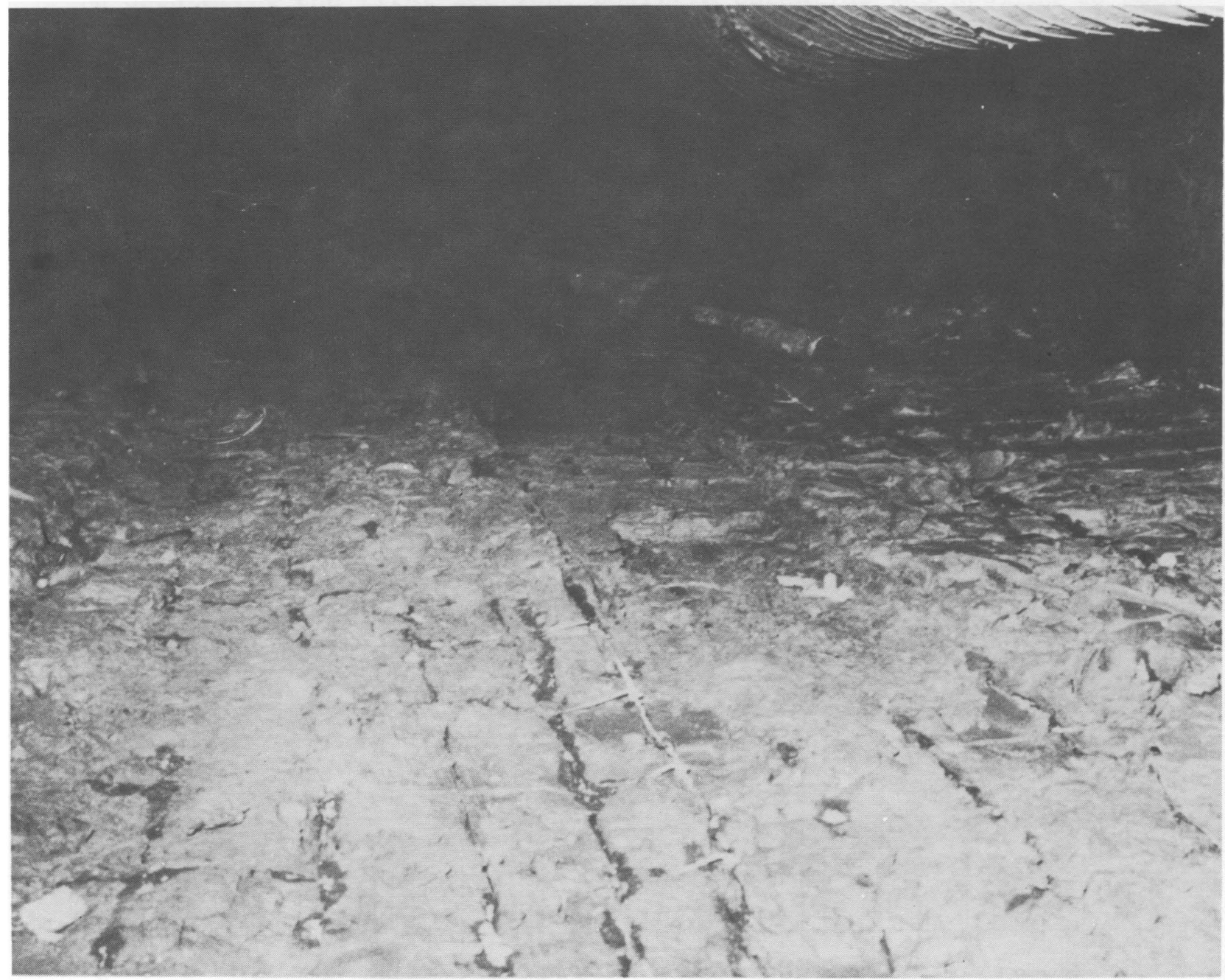

FIGURE 15. - Hardened surface at the end of treatment. 
Electrodes were arranged as in the first section and energized with $95 \mathrm{amp}$ at 230 volts. Power was applied with periodic reversal during each 30 -min cycle as follows: For $23 \mathrm{~min}$, the upper electrode was negative with the rails positive; for $1 \mathrm{~min}$, power was off; for $5 \mathrm{~min}$, the upper electrode was positive and rails, negative; and, finally, power was off for 1 min. The material was treated in this manner for about 39 hours, with a power expenditure of $39 \mathrm{kwhr} / \mathrm{yd}^{3}$. The surface hardness was considerably better than that of section 1, ranging from 420 to 20 psi with an overal1 average of about $156 \mathrm{psi}$. Except for the harder surface, however, the treated material was very similar to that in section 1. Handling effort in removal was essentially the same for both sections. A before-treatment sample from the surface near

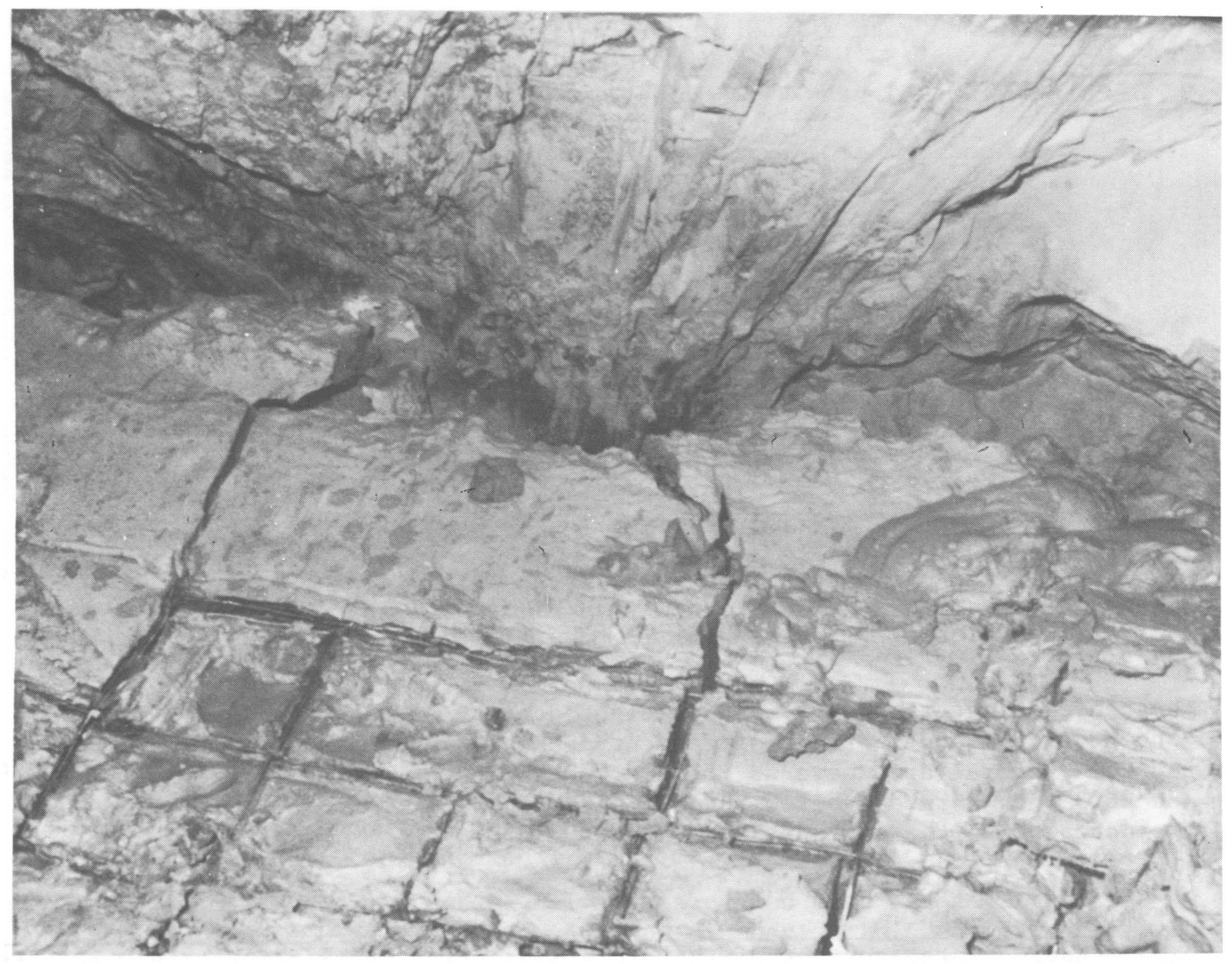

FIGURE 16. - Details of consolidation. 


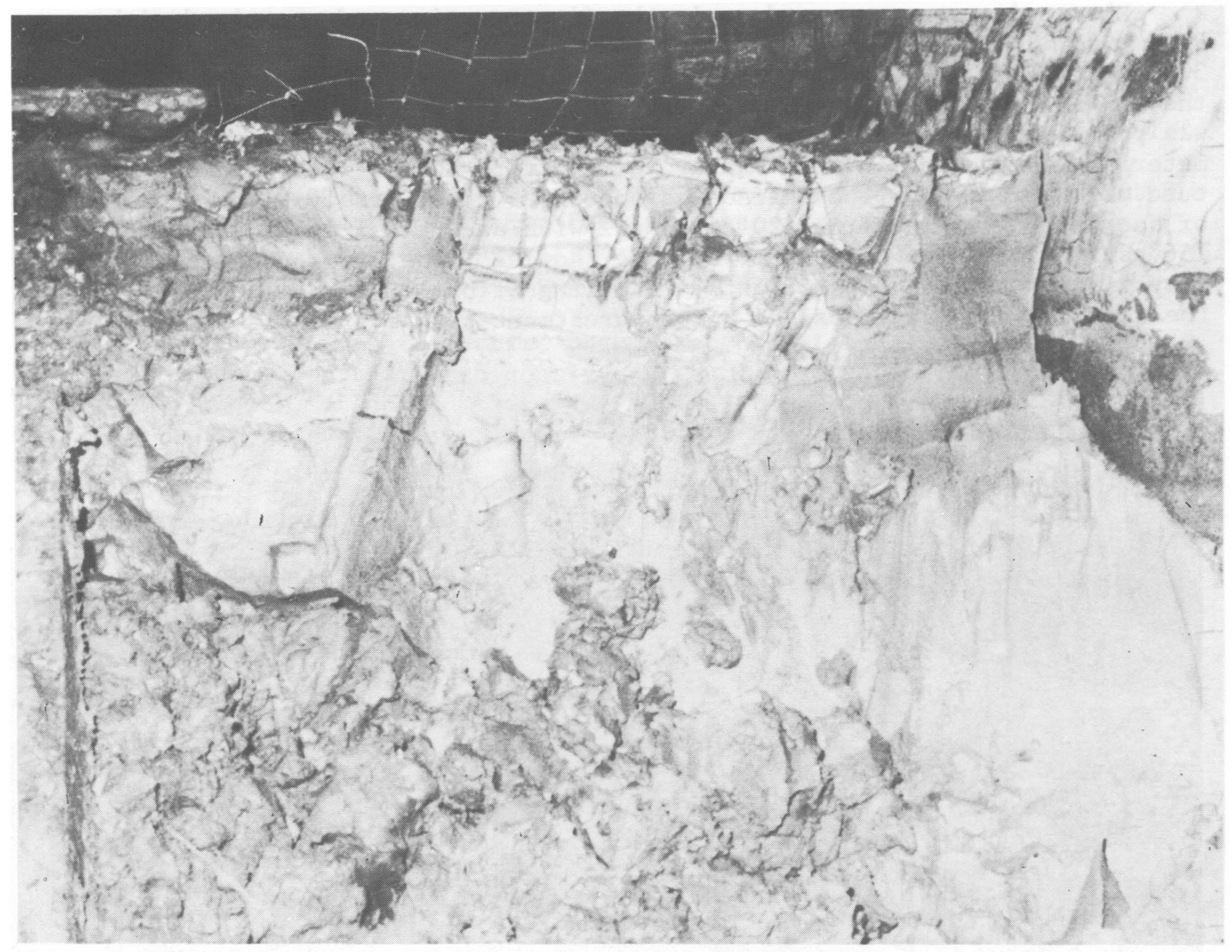

FIGURE 17. - Face of treated material during removal procedure.

the center of section 2 had a dry-weight density of $621 \mathrm{~b} / \mathrm{ft}^{3}$ and a moisture content of 54.9 pct.5 After-treatment densities and moisture contents from the same general area were as follows: 2 inches below the surface, $1121 \mathrm{~b} / \mathrm{ft}^{3}$ and 26.3 pct; 4 inches below the surface, $88.51 \mathrm{~b} / \mathrm{ft}^{3}$ and $33.1 \mathrm{pct}$; and 14 inches below the surface, $90.51 \mathrm{~b} / \mathrm{ft}^{3}$ and $37 \mathrm{pct}$.

5 The measured water content of the old slimes prior to treatment (54.9 pct) is very likely wrong (too high). The sample taken from the surface probably contained an appreciable amount of condensation water that dripped continuously from the mine roof. It was not possible to obtain a more representative sample without disturbing the deposit, and the intense heat and 100 pct humidity did not permit easy access nor encourage careful sampling. Previous laboratory studies with slimes from this mine (4) showed a 41 pct water content after decantation of surface water; the old slimes in the mine were probably at least this dry. 
Better dewatering and densification of section 2 could have been achieved with continued treatment because water was still emerging at test end. But, as in section 1 , the mine operators correctly judged the material to be adequately hardened for removal, although treatment of the third section was accomplished before removal of the hardened material in section 2 .

At a potential of 200 volts, 102 amp was applied to the third 25 -foot section with the periodic reversal of 3 min per 30 -min cycle. Water immediately oozed from the surface, and one-half hour after treatment, the surface was covered with a layer of water averaging three-eighths of an inch deep. Treatment started on a Friday afternoon and was left unattended over the weekend, about 63 hours. Monday morning inspection revealed a large quantity of water on the surface of section 3 and, unfortunately, no effective path by which the water could escape. The surface graded slightly upward and water was trapped. It is probable that this excess water on the surface and relative dryness within the material resulted in an oscillation of water with each current reversal. In any case, the surface was firm but wet. Therefore, surface channels were dug to permit water to flow away and for the next 7 hours, power was maintained on the electrodes with intermittent application as in the first section treated. At the end of this 7-hour period, the surface was firm and dry with hardness ranging from 250 psi to 20 psi. Treatment time was 70 hours with a power consumption of $46 \mathrm{kwhr} / \mathrm{yd}^{3}$. Removing the material was essentially the same as for section 1 .

When removal had progressed to the end of section 3 , it was found that the balance of the slimes in the dam could be handled with muckers. Therefore, the entire tail drift was cleaned out without further electrokinetic treatment.

A small slimes deposit in the Star mine, Wallace, Idaho, was electrokinetically dewatered and hardened in a similar manner. Results were comparable to those achieved in this test. Since periodic current reversal in previous laboratory tests had enhanced electrokinetic treatment of unclassified mill tailings, this field test was performed to determine if reversal might also be advantageous in slime treatment. No significant benefit, other than some increased surface hardness, was demonstrated.

\section{SUMMARY}

These tests demonstrated that electrokinetic treatment of underground slime deposits can sufficiently harden them to permit their removal or use as backfill. Therefore, slimes can be effectively utilized underground, either as part of unclassified tailings subjected to electrokinetic treatment in

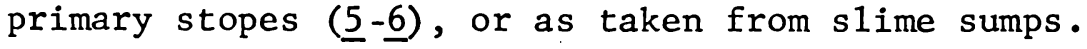

It is hoped that ultimately all slimes can be used as backfill, thereby eliminating the need for their aboveground disposal. This could best be accomplished by dewatering unclassified tailings to a much greater extent-approximately 70 wt-pct solids--before placing them in primary stopes. Such thickened slurries respond exceptionally well to electrokinetic treatment (3); they are easily transported hydraulically, and segregate to only a negligible extent on placement ( $(3)$. Electrokinetic hardening of these deposits could create a dense, high-modulus backfill that would provide greater support for mine walls, men, and equipment than is attained by the coarse classified sand now in use. 


\section{REFERENCES}

1. Applegate, L. N. Cathodic Protection. McGraw-Hi11 Book Co., Inc., New York, 1960, pp. 21-35.

2. Hodgman, C. D. (ed.). Handbook of Chemistry and Physics. Chemical Rubber Publishing Co., Cleveland, Ohio, 31st ed., 1949, p. 2398.

3. Sprute, R. H., and D. J. Kelsh. Laboratory Experiments in Electrokinetic Densification of Mill Tailings (In Two Parts) 1. Development of Equipment and Procedures. BuMines RI 7892, 1974, 72 pp.

4. Laboratory Experiments in Electrokinetic Densification of Mil1 Tailings (In Two Parts) 2. Application to Various Types and Classifications of Tailings. BuMines RI 7900, 1974, 43 pp.

5. L Limited Fie1d Tests in Electrokinetic Densification of Mil1 Tailings. BuMines RI 8034, 1975, 47 pp.

6. Electrokinetic Densification of Hydraulic Backfill--A Field Test. BuMines RI 8075, 1975, 20 pp. 


\section{APPENDIX A.--RESISTANCE CALCULATIONS FOR SLIME DEPOSITS}

Selecting proper equipment for electrokinetic treatment of slimes requires determination of the voltage and current requirements as we 11 as the power rating (in kilowatts). All of these values are directly related to the resistivity of the slimes to be treated and, the refore, reasonably accurate resistivity measurements must first be made.

Specific resistance (resistivity) is defined by the expression

$$
\rho=\frac{R A}{L},
$$

where $R$ is the resistance of a uniform conductor, $L$ is its length, A its

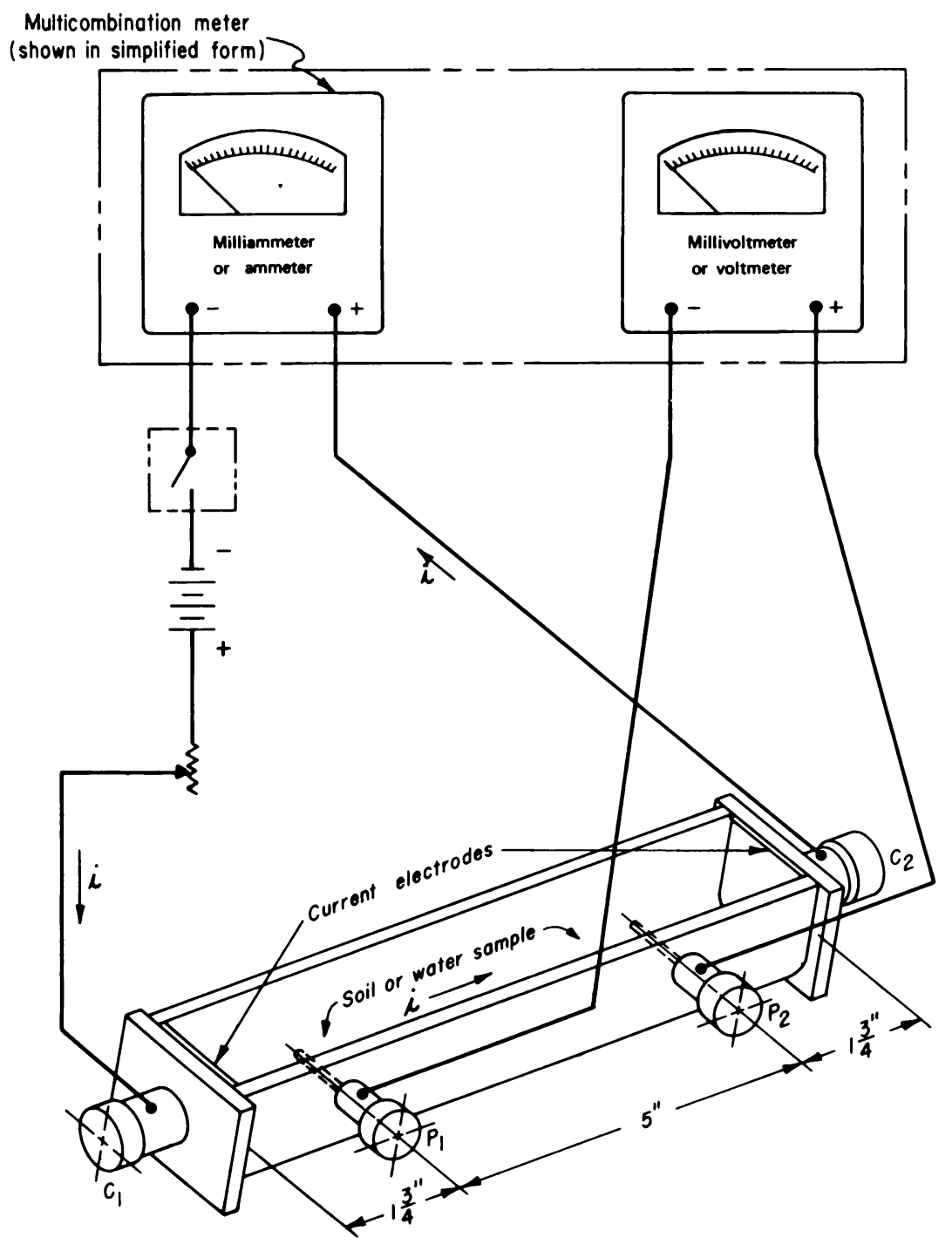

cross sectional area, and $\rho$ is the resistivity ( $\underline{2})$. Thus, a $1-\mathrm{cm}$ cube with a resistance of $1 \mathrm{ohm}$ has a specific resistance or resistivity of $1 \mathrm{ohm}-\mathrm{cm}$.

While various established methods exist for measuring resistivity of soils in nonconfined areas, applicability of these methods to confined underground areas has not been established. Therefore, resistivity measurements required under this project were performed in the laboratory using a Miller soils box.

Resistivity Measurements in Soils Box

The multicombination meter and soils box (fig. A-1) manufactured by M. C. Miller Co. was used for measuring resistivity of water and soils samples. The method is widely used, particularly in performing soil resistivity measurements in cathodic protection engineering ( $\underline{1})$.

FIGURE A-1. - Multicombination meter and soils box. 
The method consists of filling the small plastic model with the material to be measured and applying dc potential to terminals $\mathrm{C} 1$ and $\mathrm{C} 2$, causing current I to flow through the material. The flow of current develops a potential $\mathrm{E}$ across terminals $\mathrm{P} 1$ and $\mathrm{P} 2$. By $\mathrm{Ohm}$ 's law, total resistance between $\mathrm{P} 1$ and $\mathrm{P} 2$ is

$$
\mathrm{R}=\frac{\mathrm{E}}{\mathrm{I}}
$$

If equations $A-1$ and $A-2$ are combined,

$$
\frac{\rho L}{\mathrm{~A}}=\frac{\mathrm{E}}{\mathrm{I}} \text {. }
$$

The plastic mode1 dimensions are such that the quotient of $\mathrm{L} / \mathrm{A}=1$, making

$$
\rho(\text { resistivity })=\frac{E}{I} \text {. }
$$
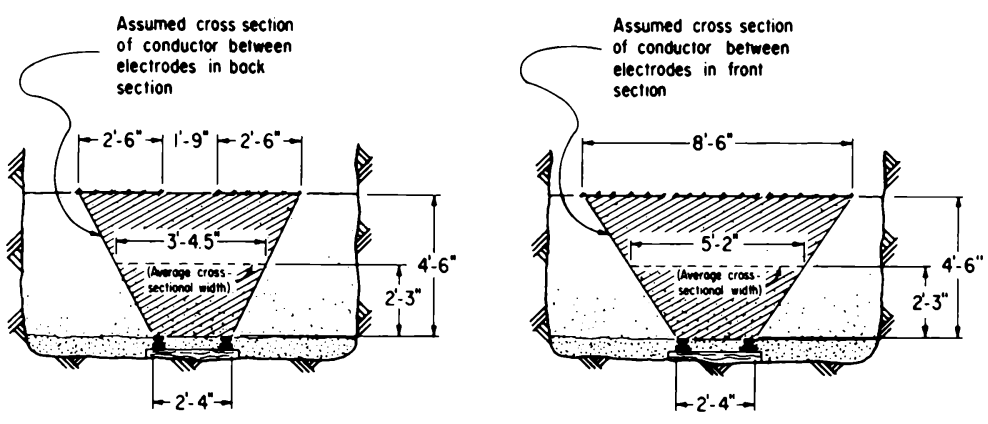

Section $8 B$

Section AA

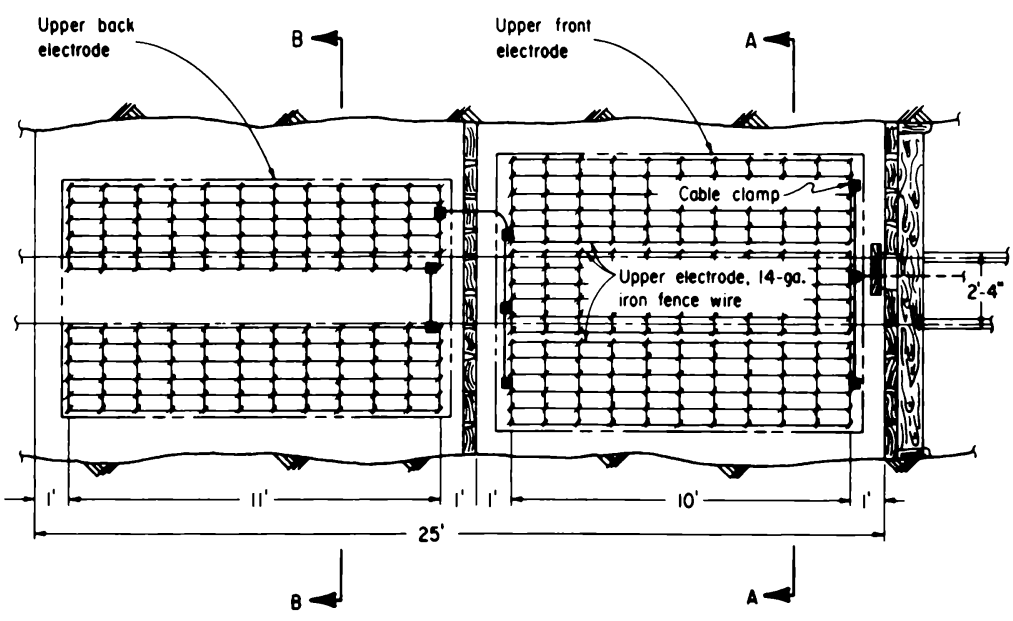

FIGURE A-2. - Resistance calculations for test 2, section 1.
Resistance Between Two Electrodes Placed in a Large Slimes Deposit

Resistivity values of representative samples from a slimes deposit measured as described in the preceding section can be used to calculate the electrical resistance of all or any portion of the sampled slimes deposit. The accuracy of these calculations is dependent on a number of important considerations and assumptions, which are lescribed in the following sample calculation.

Referring to figure 11 (setup for test 2), resistance will be calculated for the material between the two electrodes used in section 1 (fig. A-2). An indication of accuracy will be provided by comparing the calculated results with the actual measured resistance. 
As indicated in figure A-2, two different electrode arrangements are used in section 1 . The cross sectional area of the slimes through which all of the applied current is assumed to flow is indicated with crosshatching in sections $\mathrm{AA}$ and $\mathrm{BB}$. For the front section, this deposit has a depth of 4 feet 6 inches $(137 \mathrm{~cm})$, an average width of 5 feet 2 inches, and a length of 10 feet, for an average horizontal cross sectional area of $51.7 \mathrm{ft}^{2}\left(4.80 \times 10^{4}\right.$ $\left.\mathrm{cm}^{2}\right)$. This result is based on the assumption that the bottom electrode is equivalent to a flat electrode as wide as the distance across the rails, and as long as the upper electrode. A determination of the actual current paths in the area would be difficult and unwarranted in practical application. The fact that the bottom electrode has a smaller cross sectional area than that assumed in this calculation means that the calculated resistance will be too low, but by a negligibly small amount.

The cross sectional area of the deposit in the back section, section $\mathrm{BB}$, has an average width of 3 feet 4-1/2 inches, and a length of 11 feet, for a cross sectional area of about $37.1 \mathrm{ft}^{2}\left(3.45 \times 10^{4} \mathrm{~cm}^{2}\right)$. The 1-foot 9-inch space between the two lengths of fence wire is assumed to be part of a flat, continuous electrode, again with negligible consequences to the calculated resistance.

Using these values and a resistivity of $980 \mathrm{ohm}-\mathrm{cm}$,

$$
\mathrm{R}=\frac{\rho \mathrm{L}}{\mathrm{A}}=\frac{(980)(137)}{(4.80+3.45) \times 10^{4}}=1.62 \mathrm{ohms}
$$

where $R$ = resistance of the slimes between the electrodes used in test 2 , section 1 , in ohms.

$\rho=$ resistivity, in ohm-centimeters. The value of $980 \mathrm{ohm}-\mathrm{cm}$ used above is the average measured resistivity of slime samples taken within 12 inches of the surface before applying power. Previous laboratory tests showed that the resistance of these slimes would not appreciably increase the anticipated amount of dewatering. However, very large resistivity increases do occur with some tailings, and this must be considered in the design and application of power supplies.

$L=$ Distance between electrodes, in centimeters. The value of 4 feet 6 inches used in the calculation is the initial depth of slimes. This depth was reduced to about 4 feet during treatment--a factor that may be significant in design and application of power equipment. However, the increasing resistivity of slimes during treatment may be large enough to compensate for this effect.

$\mathrm{A}=$ Horizontal cross sectional area of the slimes between electrodes.

The calculated value of 1.62 ohms compares favorably with the actual electrical resistance initially present between the two electrodes used in 
section 1 , test 2 . For example, applied potential was 225 volts with a current of $125 \mathrm{amp}$; by $\mathrm{Ohm}^{\prime} \mathrm{s}$ law, the corresponding resistance is

$$
\mathrm{R}=\frac{\mathrm{E}}{\mathrm{I}} \text {, or } \frac{225}{125}=1.8 \mathrm{ohm} \text {. }
$$

The somewhat smaller calculated resistance probably reflects the error in the assumed cross sectional area of electrodes discussed previous ly and a number of other factors that were not taken into account. These would include nonuniformity of material between electrodes, a high resistance at the cathode due to generation of hydrogen, less than ideal contact between the corroded rails and the slimes, etc.

Although some rather broad assumptions were made in the foregoing computations, results do show that the electrokinetic load resistance can be estimated from resistivity measurements with reasonable accuracy if input factors are carefully considered and applied. 


\section{APPENDIX B.--POTENTIAL SAFETY HAZARDS}

The following paragraphs identify the major potential hazards associated with electrokinetic treatment of backfill in underground mines. Safety procedures are recommended to reduce or eliminate these hazards; they apply specifically to the mines and conditions encountered in these tests. Additional potential hazards, such as noxious gases and electrochemical corrosion, may be present in other mines.

\section{Hydrogen Generation as a Byproduct of Electrokinetic Treatment}

A potential hazard associated with use of electrokinetic dewatering in underground stopes is the formation of hydrogen gas at the cathode by the electrolysis reaction

$$
2 \mathrm{H}_{2} \mathrm{O}+2 \mathrm{e}^{-} \rightarrow \mathrm{H}_{2}(\mathrm{~s}) \uparrow+2 \mathrm{OH}^{-} \text {. }
$$

This flammable gas, if present in concentrations greater than 4 vol-pct in air, can be ignited by a spark or spontaneous ignition, particularly if temperatures are high and catalytic surfaces (for example, noble metals) are present. Ignition can trigger explosions whose force will depend on the concentrations and amounts of hydrogen and oxygen present.

Keeping the hydrogen concentration in air below 4 vol-pct would appear to be the best way of eliminating the hazard underground. This means that stope ventilation must be adequate during electrokinetic treatment. A sample calculation may demonstrate the extent of this requirement.

If $\mathrm{dc}$ current is applied continuous ly at $240 \mathrm{amp}$ and hydrogen generation is assumed to be the only reaction that occurs at the cathode, 8.95 grams of hydrogen will be produced each hour (240 amp $\times 3,600$ seconds $\div 96,500$ amp$\mathrm{sec} / \mathrm{g} \mathrm{H})$. If all this gas escaped to the air above the stope and remained there (that is, no ventilation), and the volume of air in the stope was $200 \mathrm{ft}^{3}$ (5,660 liters), 20.2 grams of hydrogen would be needed to create a concentration of 4 vol-pct. This amount would be generated in 2 hours and 15 minutes $\left(\frac{20.2}{8.95}\right)$. Therefore, treatment times in excess of this require ventilation or a correspondingly larger air volume above the stope.

\section{Detonation of Blasting Caps}

Accidental detonation of blasting caps could occur with inadvertent transmission of dc potentials (by pipe, metallic ore vein, etc.) from a stope being electrokinetically dewatered to other areas such as a neighboring stope. Precautions to minimize or eliminate this hazard should include the following:

1. Unless potential gradients have been accurately determined by measurement or calculation, keep electrodes away from the stope walls by a distance equal to or slightly greater than the spacing between electrodes. The potential at the stope walls will then be relatively low, equal to applied 
potential less IR (current $X$ resistance) drop through the material between the electrode and the stope wall.

2. Remove al1 metal objects from the stope wa11, thus eliminating paths by which current might be transmitted from the stope to other areas.

3. Equip dc power supply units with fail-safe timers to automatically interrupt power application; for example, from 1 hour before blasting until one-half hour after the blasting period.

4. Equip the dc power supplies with sensitive ground detecting equipment that will stop and lock out the power supply unit if ground current exceeds a predetermined safe level.

5. During electrokinetic treatment, monitor adjacent areas for evidence of stray potential.

\section{Physica1 Contact of Personne1 With High-Voltage Equipment}

The danger of electrical shock to mine personnel can be effectively eliminated by following some commonsense procedures and incorporating safety features into the design of electrical equipment.

1. Clearly marked barricades should be erected to prohibit all access to the stope during treatment. Red lights at the barricades should indicate when power is being applied at the stope.

2. Switching circuits should be designed to prevent anyone other than the operator at the stope from applying power to the electrodes.

3. Stope operators should be skilled electricians, well versed in general safety procedures for high-voltage equipment, underground mining, and the electrokinetic process itself.

Figures $B-1$ and $B-2$ show an operational power unit used by the Hecla Mining Co. for electrokinetic treatment of slimes. 


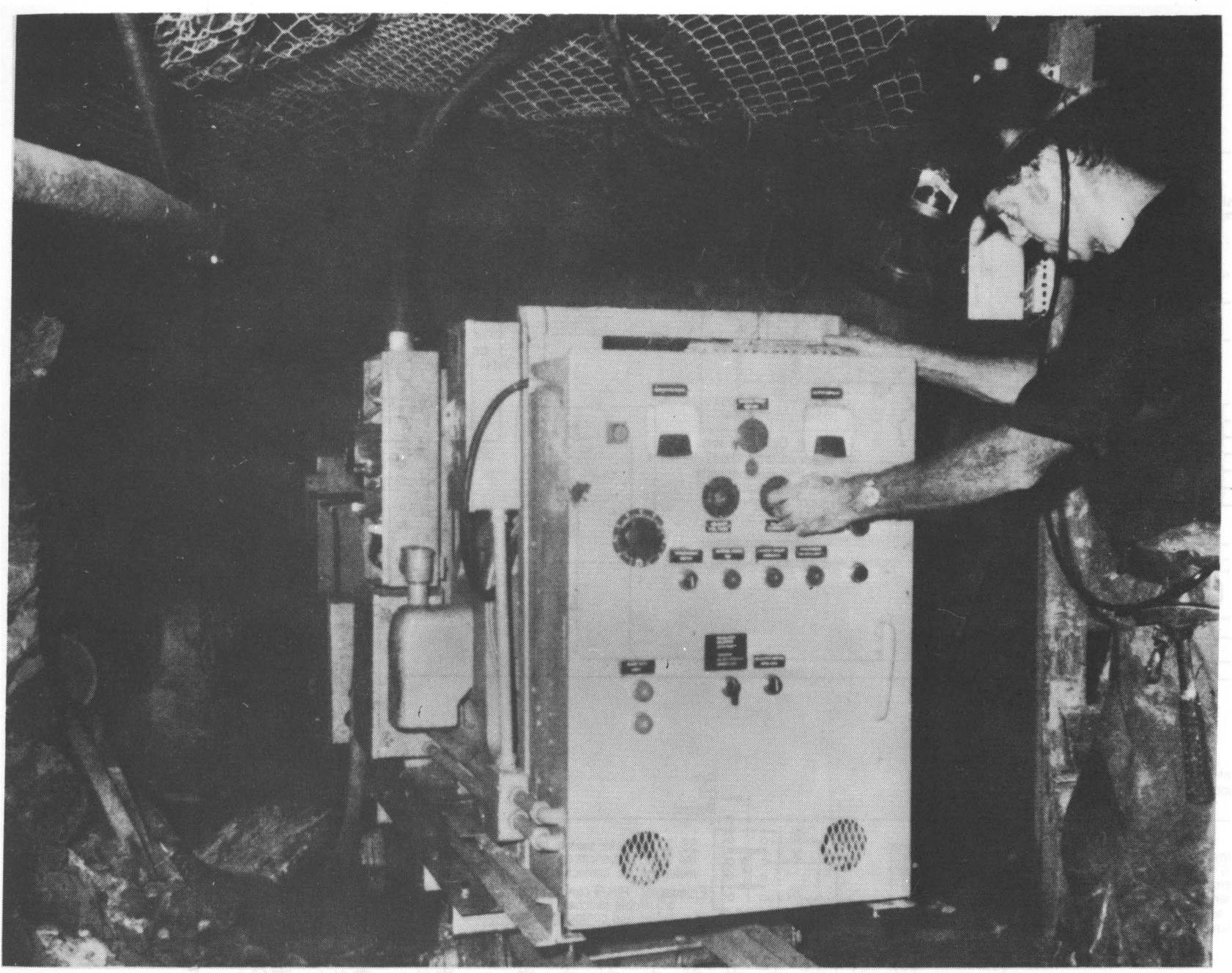

FIGURE B-1. - Motor-generator unit used for treatment of slurries, $60 \mathrm{kw}$. 


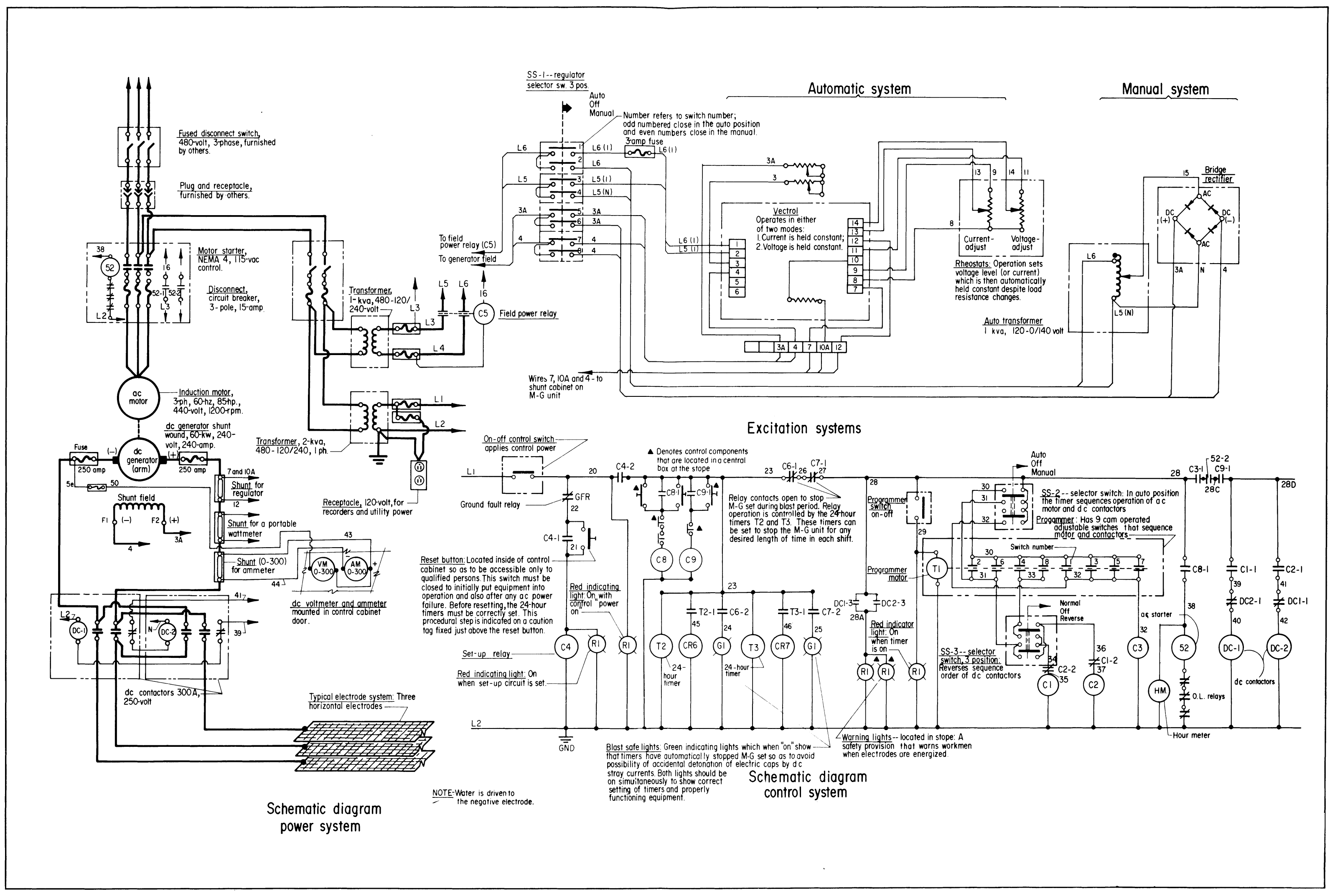





